\title{
Cognitive Maps Beyond the Hippocampus
}

\author{
A. David Redish and David S. Touretzky* \\ Computer Science Department and Center for the Neural \\ Basis of Cognition, Carnegie Mellon University, \\ Pittsburgh, Pennsylvania
}

\begin{abstract}
We present a conceptual framework for the role of the hippocampus and its afferent and efferent structures in rodent navigation. 0 ur proposal is compatible with the behavioral, neurophysiological, anatomical, and neuropharmacological literature, and suggests a number of practical experiments that could support or refute it.

We begin with a review of place cells and how the place code for an environment might be aligned with sensory cues and updated by selfmotion information. The existence of place fields in the dark suggests that location information is maintained by path integration, which requires an internal representation of direction of motion. This leads to a consideration of the organization of the rodent head direction system, and thence into a discussion of the computational structure and anatomical locus of the path integrator.

If the place code is used in navigation, there must be a mechanism for selecting an action based on this information. We review evidence that the nucleus accumbens subserves this function. From there, we move to interactions between the hippocampal system and the environment, emphasizing mechanisms for learning novel environments and for aligning the various subsystems upon re-entry into familiar environments. We conclude with a discussion of the relationship between navigation and declarative memory. Hippocampus 7:15-35, 1997.

(c) 1997 Wiley-Liss, Inc.
\end{abstract}

KEY WORDS: spatial cognition; navigation; path integration; head direction cells; place cells; hippocampal formation; subicular complex

\section{INTRODUCTION}

In their 1978 book, The H ippocampus as a Cognitive M ap, 0 'Keefe and $N$ adel suggested that the rodent uses three mechanisms for spatial reasoning: routes and guidances (which are together called taxon systems) and cognitive maps (called thelocal esystem). They suggested the hippocampus as the locus of the map used by the locale system. In this paper, we explore the role the hippocampus and its afferent and efferent structures might play in a complete locale navigation system.

Early work (Papez, 1937; Isaacson, 1974) suggested that the limbic system, including the hippocampus, mediated the emotional state of the animal. M ore recently, a number of al ternative theories have been proposed, including that the hippocampus serves as a comparator in a system that identifies novel and unexpected occurrences (Gray, 1982), that it forms associations among sets of spatially and temporally disparate cues (called

\footnotetext{
*Correspondence to: David S. Touretzky, Computer Science Department and Center for the Neural Basis of Cognition, Carnegie Mellon University, Pittsburgh, PA 15213-3891.

Accepted for publication 2 August 1996
}

configural associations) (Sutherland and Rudy, 1989), that it both compresses and differentiates representations (Gluck and Myers, 1993; O'Reilly and McClelland, 1994), that it encodes an egocentric representation of visible landmarks (M cN aughton et al., 1989), or that it stores a cognitive map (Tolman, 1948) for navigation (O 'Keefe and N adel, 1978).

Early studies on humans with temporal lobe lesions, such as that of HM (Scoville and Milner, 1957), suggested that the hippocampal system may be involved in declarative or episodic memory. $\mathrm{H}$ owever, the lesions in these early studies were found to be very extensive, including much more than just the hippocampus. Recently, though, a number of researchers have suggested that the early data were correct in implicating the hippocampus as playing a key role in a declarative or episodic memory system (Squire and Zola-Morgan, 1988; Buzsaki, 1989; Eichenbaum et al., 1992; Cohen and Eichenbaum, 1993; Zola-M organ and Squire, 1993; McClelland et al., 1995). According to the declarative memory theory, memories of events in time and space (i.e. episodes) are consolidated by the hippocampal formation but stored in cortex. See C ohen and Eichenbaum (1993) for a review.

In this paper, we start from the hypothesis that the hippocampus serves as the nexus of a locale navigation system. From this, we are able to explain data relating systematic variations in cell firing rate to factors such as location of the animal, direction of trajectory, environment, task, and stage of task. A cell tuned to all these factors would bewell-situated to encode an episode.

Although hippocampal studies have been performed on rodents, rabbits, and both human- and non-human primates, we will discuss only rodents. We do this for simplicity, because we wish to talk about an entire system, not just hippocampus, and because there is more than adequate data on rodents.

\section{OVERVIEW}

In (Touretzky and Redish, 1996), we presented a systems-level model of rodent navigation that was compatible with a wide variety of behavioral and 


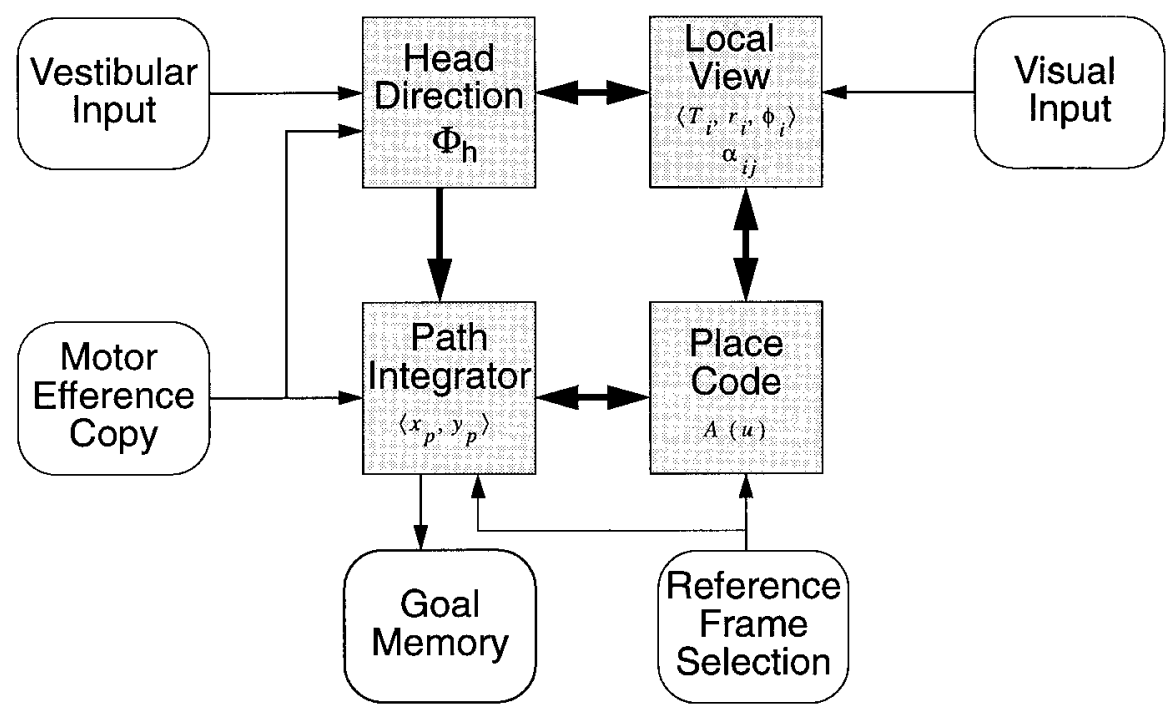

FIGURE 1. Systems-level model of rodent navigation originally presented in Touretzky and Redish (1996).

neurophysiological results (see Fig. 1). We begin with a review of the major points in this systems-level model. We then expand this model to show the different computations performed by each subsystem (Fig. 2) and refinethis expanded systems-level model to produce a conceptual framework that is also compatible with an extensive literature of anatomical, neuropharmacological, and lesion data (see Fig. 3).

\section{The Original Model}

The main claim of our model is that navigation can be explained by an interaction between four different spatial representations: a representation of the animal's relationship to local landmarks in its environment called the local view (M CN aughton, 1989), a metric representation of position that accomodates vector arithmetic (the path integrator), a distributed representation of position (the place code) that ties local views to path integrator coordinates, and a representation of head direction. Additionally, this model requires a goal subsystem that accomodates trajectory planning, and a reference frame sel ection subsystem which allows the animal to navigate in different environments.

These abstract subsystems should not be expected to be anatomically localized; their functions are likely to be distributed across several brain structures.

The local view of an environment is what can be seen from a particular viewing position. The local view subsystem represents the animal's relationship to various visible landmarks. It should at a minimum include representations of distance, bearing and type for each landmark. With a sufficiently rich set of cues and no pathological symmetries in the environment, each local view describes a unique place.

The path integrator allows the animal to plan a trajectory back to its starting location from any place in the environment without using environmental cues. The information represented in the path integrator (location relative to a reference point) can be used to drive place cells in the dark (O 'K eefe, 1976; M cN aughton et al., 1991; Muller et al., 1991a; Wan et al., 1994a; Wan et al., 1994b; M cN aughton et al., 1994a; M cN aughton et al., 1996; Touretzky and Redish, 1996).

The place code represents the location of an animal in an environment. It is obviously realized by place cells in the hippocampus ( 0 'K eefe and D ostrovsky, 1971; see M uller et al., 1991a for a review). In (Touretzky and Redish, 1996; Redish and Touretzky, 1996), we suggest that parallel relaxation ${ }^{1}$ can be used to ensure that the population of place cells accurately encodes the animal's location in an environment. Wilson and $\mathrm{M} \mathrm{CN}$ aughton (1993) have shown that location can be determined to within $1 \mathrm{~cm}$ from the activity of place cells in the hippocampus.

In order for path integration to be possible, the animal must have a representation of its direction of motion. Cells that have a unimodal tuning to head direction independent of location have been recorded in several areas of the rat brain (Taube et al., 1990a; Taube et al., 1990b; Chen, 1991; M izumori and Williams, 1993; W iener, 1993; Chen et al., 1994a; Chen et al., 1994b; Blair and Sharp, 1995a; M izumori and Cooper, 1995; K nierim et al., 1995; Taube, 1995). These head direction cells provide a sort of internal compass.

\section{Functional Expansion of the Model}

The subsystems in the original model, presented in Figure 1, each comprise a collection of functions. For example, the head

1Parallel relaxation in a neural network is a process where the active units simultaneously apply constraints to each other and adjust their activity levels until the system as a whole settles into a locally optimum state in which as many constraints as possible are satisfied. 


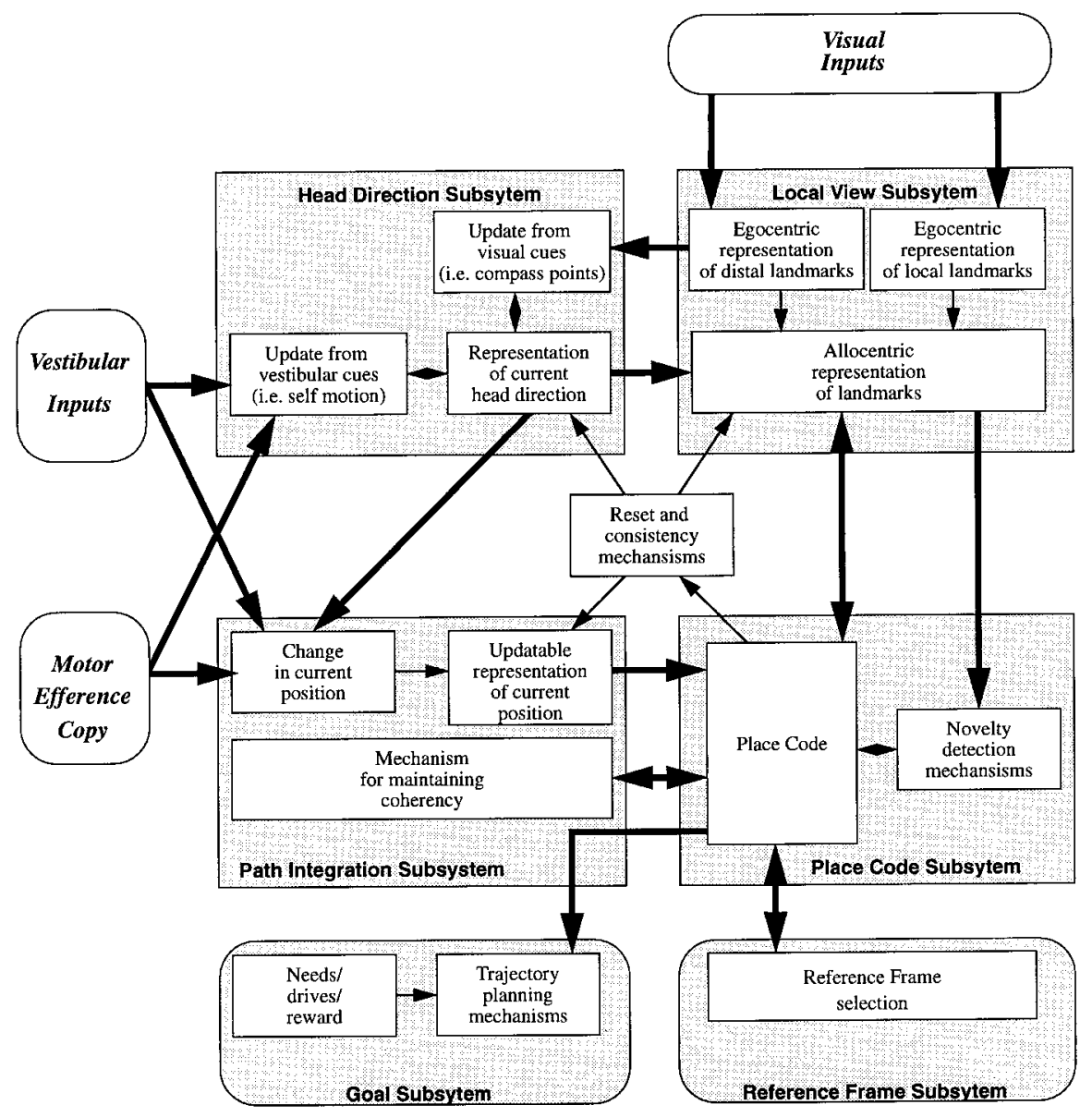

FIGURE 2. Expansion of the framework presented in Figure 1, showing the computations performed by each subsystem.

direction subsystem necessarily includes mechanisms for updating the representation from visual cues (both local and distal landmarks) as well as from vestibular and other self motion cues. Similarly, the path integrator subsystem includes mechanisms for updating the current representation of position from self-motion cues, and for carrying information about the location of the animal to the goal subsystem. In addition, the path integrator's spatial representation may help to shape the place code, i.e., in a coherent place code all currently active place cells should have place fields with similar path integrator coordinates.

Figure 2 shows the functional expansion of the model. The subsystems are shown in grey with the functions they encompass marked. The connections included in Figure 1 are marked by heavy lines in Figure 2. Each of the functions presented in Figure 2 should be expected to be handled by a different anatomical system consisting of a few interacting brain structures.

\section{The Full Conceptual Framework}

The expanded framework in Figure 2 is still at the level of abstract functional boxes that must somehow be realized by brain structures. We now proceed to delineate those structures and how they accomplish their respective tasks. In addition, the framework presented has implications for how the system as a whole interacts with the environment.

We begin with a summary of the key hypotheses. We are not the first to suggest some of these (citations are given in each section), but we demonstrate that they 1 ) are consistent with the available data, 2) are compatible with each other, and 3) make explicit predictions that can be tested with current technologies.

Place code. The place code, realized by place cells in the superficial layers of entorhinal cortex and the hippocampus proper (including both CA3 and CA1), serves to associate path integrator coordinates with local view information.

Sensory cues. Local view. Local view information enters the place code via the deep layers of entorhinal cortex.

I diothetic cues Path integration. Path integration in the rodent is accomplished via a loop including the hippocampus proper, the subiculum, the parasubiculum, and the superficial layers of the entorhinal cortex. Self-motion cues may enter the system from posterior cingulate cortex.

$\mathrm{H}$ ead direction. Current head direction is maintained in 


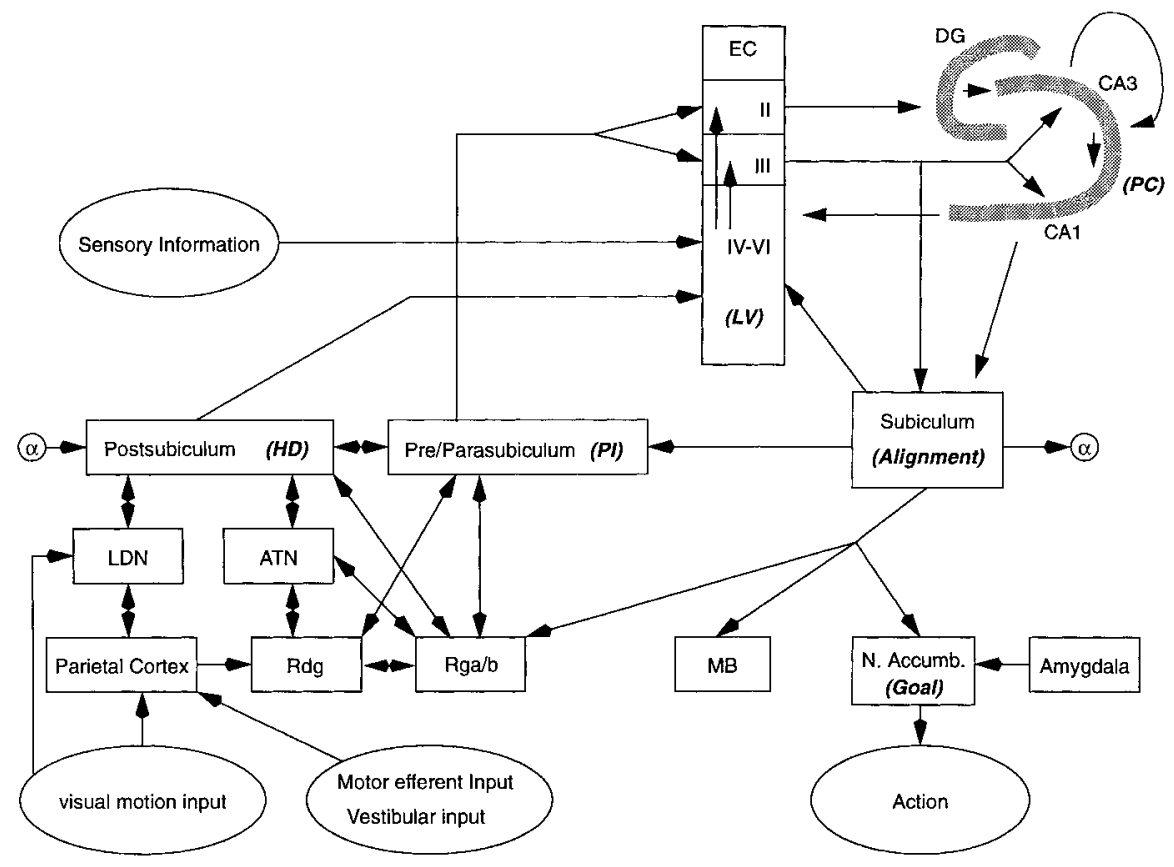

FIGURE 3. Anatomical realization of our conceptual framework. Not all connections are shown. EC, entorhinal cortex; DG, dentate gyrus; LDN, lateral dorsal nucleus of thalamus; ATN, anterior thalamic nuclei; Rdg, dysgranular retrosplenial cortex; $\mathrm{Rga} / \mathrm{b}$, granular retrosplenial cortex; N. Accumb., nucleus accumbens; M B, mammillary bodies. Together Rdg and Rga/b constitute the posterior cingulate cortex. Subiculum projects to postsubiculum (marked by $\alpha$ ). Local view (LV) is realized by inputs from high-level

sensory cortices and the deep layers of entorhinal cortex. The place code (PC) is realized by sup-EC and the hippocampus proper. The path integrator $(\mathrm{PI})$ is realized by a loop including hippocampus, subiculum, parasubiculum, and sup-EC. The head direction system (HD) is realized by interactions among PoS, LDN, and ATN. The goal subsystem ( $G$ oal) is realized by the nucleus accumbens. Alignment occurs through the subiculum.

other. We offer possible mechanisms to ensure that the system works as an integrated whole, and suggest that the subiculum mediates this alignment function.

The full model is shown in Figure 3. We now proceed to detail each of these subsystems and compare our hypotheses with the data.

\section{PLACE CELLS}

For spatial tasks, the first-order correlate of spikes fired by CA3 and CA1 cells in hippocampus is the location of the rat: each cell fires when the animal is in a specific place (called the place field of the cell, O 'K eefe and D ostrovsky, 1971, see M uller et al., 1991a for a review). The place fields of place cells are generally compact (having only one peak) and continuous. ${ }^{2} \mathrm{~T}$ he ensemble activity of

2Place cells do occasionally show multiple place fields. However, the number of cells with subfields is highest when recorded with a single-wire electrode, and diminishes when recorded with a stereotrode (McN aughton et al., 1983b) or a tetrode (Leonard and McNaughton, 1990; Wilson and McNaughton, 1993). This implies that many (though clearly not all) of the multiple fields seen are really multiple place cells (Leonard and McNaughton, 1990). 
a population of place cells encodes the rat's location in the arena (W ilson and $\mathrm{M}$ CN aughton, 1993).

Approximately $15 \%$ of hippocampal pyramidal cells identified during slow wave sleep show place fields in any given environment (Thompson and Best, 1989). When tested in two distinct environments, many cells will show fields in only one environment, and when a cell exhibits fields in both, the locations of the two fields will be uncorrelated (Kubie and Ranck, 1983; M uller and Kubie, 1987; O 'Keefe and Speakman, 1987; Thompson and Best, 1989). The number of place cells found to have fields in more than one environment is consistent with the hypothesis that the active subset is chosen randomly from the population, and that each environment's active subset is chosen independently (T hompson and Best, 1989).

Although originally reported in CA3 and CA1, place cells have also been found in the superior layers of entorhinal cortex ( $Q$ uirk et al., 1992), the dentate gyrus (Jung and $M C N$ aughton, 1993), the subiculum (Sharp and Green, 1994; Sharp, 1995), and the parasubiculum (Taube, 1996).

\section{Formation of Place Codes}

We have hypothesized that an important role of the place code is the association of sensory with idiothetic cues (Wan et al., 1994b). Once this association has been established, a rat can correct for path integrator drift by retrieving the coordinates associated with its current local view (Wan et al., 1994b; Touretzky and Redish, 1996). But how is this association to be made? If the path integrator drifts as the animal explores an environment, an incorrect association will be stored in the place representation. We have seen that gerbils exploring a novel environment regularly return to their entry point (unpublished observations). We surmise that in novel environments, animals correct for drift by realigning their path integrator at certain distinguished locations (see discussion of Familiar Environments, below) where the correct association between coordinates and local view has already been made.

This leads us to consider how hippocampal place fields develop. Although they can be seen the first time the animal enters an environment ( $\mathrm{Hill}, 1978)$, place fields in an unexplored environment are neither as reliable nor as accurate as in a well-explored environment (Wilson and McN aughton, 1993). Austin et al. (1993) found that the sizes of place fields decreased with experience in an arena, and that directional selectivity increased. Wilson and M CN aughton (1993) report that over a 20 minute recording session in a novel environment, the number of cells showing place fields increased by approximately $50 \%$, and the accuracy and reliability of the fields also increased. This implies that the place representation is partly hard-wired and partly learned, and that the learning occurs quickly (over the course of tens of minutes). As suggested by Sharp (1991), this is consistent with a competitive learning mechanism (G rossberg, 1976; Kohonen, 1984; Rumelhart and Zipser, 1986) operating on local view information. But the learning process must also be taking note of the path integrator coordinate representation.

\section{SENSORY CUES: LOCAL VIEW}

Place cells are sensitive to visual cues (see M uller et al., 1991a, for a review). W hen distal cues, such as wall hangings, are moved around the room, place fields tend to rotate around the center of the arena with them (O 'Keefe and Conway, 1978). Similarly, place cells have been shown to be sensitive to translations of local cues, such as objects moved around the arena (Gothard et al., 1994).

In addition, place cells are sensitive to local surface orientation: M uller et al. (1987) report cells with place fields al ong the wall of a cylindrical arena. The interior edges of these fields are concave, i.e. the fields "hug" the arena wall. O ne possible explanation is that these cells are sensitive to the surface orientation of the wall. An alternative hypothesis is that they are tuned to distal landmarks such that the center of the place field is external to the maze and only a small edge of the place field is accessible to the animal. But this alternative mechanism cannot generate place fields with concave sides opposite the wall, only convex. In order to generate concave sides, place cells must be tuned to surfaces. Since there are also place fields with convex sides, cells must differ in the types of cues they respond to, some cells must be tuned to point-type and some to surface-type landmarks.

0 ther manipulations of the local surface orientation have been explored. M uller and Kubie (1987) found that when a barrier was added to the cylinder, the firing rates of nine of 10 cells whose fields intersected the barrier diminished. The remaining cell increased its firing rate. Substituting a transparent barrier didn't affect the results. If only the base was put into the place field, there was no effect on firing rate. Barriers outside the place field al so had no effect. This suggests that place cells are tuned to local surface orientation only, i.e., they are not sensitive to orientations of distant surfaces.

W hen place cells are recorded in two environments, a rectangular and a cylindrical arena, such that both should produce similar visual sensations (same distal landmarks, both with a white cue card covering $90-100^{\circ}$ of arc), most place cells that have a field in one arena don't have a field in the other (M uller and Kubie, 1987). Those cells that do have fields in both have very different fields in each. Again, this suggests that place cells are sensitive to the local surface orientation. Interestingly, neither subicular nor entorhinal place cells are sensitive to this environmental change ( $Q$ uirk et al., 1992; Sharp, 1995). It is not known whether subicular or entorhinal place cells are sensitive to barriers in their place fields.

Behavioral experiments have also shown that rodents are more sensitive to the geometry of the arena and surrounding cues than to non-geometric information (G allistel, 1990). Cheng (1986) tried to train rats to choose one corner of a rectangular environment that had unique sensory cues (odor, surface texture, number of lighted pinholes) at each corner. H e disoriented the rats before each trial, and found that the rats were only able to distinguish the correct corner and its opposite from the other two. Both the correct corner and its opposite were formed by a long wall on the left and a shorter wall on the right (or vice versa for someanimals), 
a purely geometric property. The rats were unable to distinguish the correct corner from the one diagonally opposite, even though the two had markedly different non-geometric properties.

All of this implies that the hippocampus should receive input from high-level sensory cortices, which it does: dentate gyrus, CA3 and CA1 receive glutamatergic input from the superficial layers of the entorhinal cortex. Entorhinal cortex in the rat is divided into six layers which are traditionally understood in terms of superficial layers (I-III, sup-EC) and deep layers (IV-VI, deep-EC) (Kohler, 1986; Kohler, 1988; Jones, 1993; Witter, 1993). The deep layers of EC receive highly processed input from sensory and association areas (Kohler, 1986; Kohler, 1988). $D$ eep-EC then projects to sup-EC and thence into the hippocampus via the perforant path. See (Amaral, 1993; Jones, 1993; W itter, 1993) for reviews. Wetherefore suggest that the local view subsystem in Figure 2 is realized by cells in the deep layers of EC (Fig. 3).

As shown in Figure 2, the local view must receive information about the current head direction. $D$ eep-EC receives afferents from the postsubiculum (van Groen and Wyss, 1990) which we will show represents the current head direction (see Representations of $\mathrm{H}$ ead Direction, below).

There are broadly tuned place cells in entorhinal cortex, but they are only found in the superficial layers (Q uirk et al., 1992). The perforant path arises from cells in layers II (synapsing on DG and $C A 3$ ) and III (synapsing on CA3, CA1, and subiculum) (Kohler, 1986; Kohler, 1988; Amaral, 1993; Jones, 1993; Witter, 1993). The connections from $C A 1$ and subiculum to $E C$ return to deep-EC (Amaral, 1993; Jones, 1993); the connection from deep-EC to sup-EC completes the loop (Kohler, 1986; Kohler, 1988). See Figure 3. Place fields in sup-EC are larger and more diffuse than those in $\mathrm{CA} 3$ and $\mathrm{CA} 1$, but they are true place fields, in that they are compact, continuous fields with centers that do not change from session to session (Q uirk et al., 1992).

This suggests that place cells in sup-EC are not part of the local view subsystem, but are part of the place code instead. This means that they should receive input from the path integrator; we will show below that they do (see Anatomy of the Path Integrator). It also makes predictions about their activity (for example, that sup-EC place cells should be active in the dark); our predictions are summarized at the end (see D iscussion).

An interesting question is whether deep-EC cells will continue to be active in the dark. Although our theory is compatible with this result (cells in deep-EC could be driven by local view information reconstructed from the place code), if deep-EC is found not to be active in the dark, that would be strong evidence that it is part of a local view system.

The neural level representation of complex visual scenes is poorly understood at present, so it is not clear what the activity of deep-EC cells should look like. We can predict, however, that the activity of deep-EC cells will be correlated to information about the local view, that is to distance, bearing, and type of local landmarks.

Q uirk et al. (1992) only recorded from four cells in deep-EC, but found that these cells had a lower average spatial coherence (a measure of the compactness of the place field) than sup-EC cells.
However, Mizumori et al. (1992) report that deep-EC cells do show place fields with similar place specificities (a different measure of the compactness of the place field) to sup-EC cells. Barnes et al. (1990) also found place cells in EC but made no distinction between cells in superior and deep layers. We believe that more experiments are needed before anything can be concluded about the deep layers of EC.

\section{IDIOTHETIC CUES: PATH INTEGRATION}

Path integration implies the ability to return directly to a starting point from any location, even in the dark or after a long circuitous route (see Gallistel, 1990, and M aurer and Seguinot, 1995, for reviews). This ability has been shown in gerbils (M ittelstaedt and M ittelstaedt, 1980), hamsters (Etienne, 1987; Etienne, 1992), house mice (Alyan and Jander, 1994), and insects (Wehner and Srinivasan, 1981), as well as dogs, cats, and humans (Beritashvili, 1965). ${ }^{3}$

A number of researchers have suggested that place cell firing in the absence of cues may be the result of path integration ( 0 ' $K$ eefe, 1976; M cN aughton et al., 1991; M uller et al., 1991a; M cN aughton et al., 1994a; Wan et al., 1994b; M cN aughton et al., 1996; Touretzky and Redish, 1996). In direct support of this hypothesis, Sharp et al. (1995) report that place cells are sensitive to vestibular and visual motion cues.

It has long been known that place fields persist when prominent visual cues are removed (Muller and Kubie, 1987; O 'Keefe and Speakman, 1987; Leonard and M cN aughton, 1990) or when the animal navigates in the dark ( $\mathrm{M}$ cN aughton et al., 1989; Q uirk et al., 1990; M arkus et al., 1994). In a circular or radial maze, place fields may be rotated around the center of the arena by a random amount in the absence of light, but remain the same distance from the wall as in the normal, lighted condition (Muller and Kubie, 1987; M cN aughton et al., 1989; Q uirk et al., 1990). This implies that the cells are not still being driven by non-visual cues; if they were, then the fields would not move at all. It also implies that the animals are not treating the dark environment as a new environment; if they were, then place fields should move to new, unrelated locations.

The path integration subsystem in Figure 2 includes, in addition to a mechanism for updating current position, a mechanism for maintaining coherency of the place code. This latter component will be addressed below (see Familiar Environments).

${ }^{3}$ Although we know of no experiments specifically examining path integration in rats, data from Carr and Watson showing that rats could navigate a Hampton-Court maze without ever touching the walls (Watson, 1907), that even sensory-deprived rats could learn to navigate the maze (Watson, 1907; Carr, 1917), and that well-trained rats run into walls when the lengths of the corridors are shortened (Carr and Watson, 1908) imply that these rats may be using path integration to solve the maze task. 


\section{Models of Path Integration}

A number of mechanisms have been proposed to underlie the path integration ability of rodents. These include table lookup ( $\mathrm{M}$ CN aughton and $\mathrm{N}$ adel, 1990), linear associators ( $\mathrm{M}$ CN aughton et al., 1991; M cN aughton et al., 1994a), vector addition (Touretzky et al., 1993; Wan et al., 1994b; Touretzky and Redish, 1996), and $2 \mathrm{D}$ attractor networks (Samsonovich and $\mathrm{MCN}$ aughton, 1995; M cN aughton et al., 1996).

According to the lookup table theory, representations of all possible locations are combined with representations of all possible actions in an associative memory. When the animal performs some action, the new position is found by looking up the current position and the action in the associative memory. The linear associator theory is a continuous version of the same idea; it interpolates between stored values to provide a more accurate result. No realistic simulations of these mechanisms for path integration have been reported.

The vector addition hypothesis suggests that the animal maintains a vector to its current location from the origin of the coordinate system, and updates this representation by adding in a motor action vector every time it takes a step. M ittelstaedt (1983) and Gallistel (1990) have both pointed out that for reasons of numerical stability, path integration should be done in a Cartesian coordinate system. With polar coordinates, position error grows exponentially as motion vectors are calculated and added. We have proposed (Touretzky et al., 1993; Redish and Touretzky, 1994) a neurally plausible mechanism for vector arithmetic based on the population vector (G eorgopoulos et al., 1983) which is not strictly C artesian or polar, but in which the error grows linearly. ${ }^{4}$

The 2D attractor model of path integration uses a "hill of activation" that moves over a two-dimensional array of units. The location of the peak indicates the animal's present position. This style of representation raises questions about edge effects and increasing coarseness of representation with distance from the origin of the coordinate system which we won't explore here. Its prime advantages are architectural simplicity and neural plausibility.

\section{Representations of Head Direction}

In order for an animal to add a motor action vector to the vector stored in the path integrator, it must know in what direction it is moving. Cells with firing rates reflecting head direction (H D ) have been discovered in a number of structures in the rodent brain: postsubiculum (PoS: Taube et al., 1990a), anterior thalamic nuclei (ATN: McNaughton et al., 1994a; Knierim et al., 1995; Taube, 1995), the lateral dorsal nucleus of

\footnotetext{
${ }^{4}$ Because errors in the path integrator can be corrected from local view information via the association stored in the place code (Wan et al., 1994a; Tourtezky and Redish, 1996), there may be some systematic error in the path integrator which is corrected in the light. Maurer and Seguinot (1995) review data showing that systematic errors in path integration do exist for a variety of species.
}

the thalamus (LD N : M izumori and Williams, 1993) and to a lesser extent, parietal and cingulate cortex (Chen et al., 1994b; Chen et al., 1994a) and striatum (W iener, 1993). When multiple head direction cells have been recorded simultaneously, the difference between their preferred directions is a constant across all environments tested (Taube et al., 1990b; G oodridge and Taube, 1995). We can therefore talk about the precession of the head direction code as a whole.

If an environment is familiar, the place code will be similar to that on previous encounters. Since the place code is influenced by the path integrator, it too must be aligned with previous encounters with that environment. We should therefore expect head direction cells to be sensitive to the same directional cues of various types that place cells are. $\mathrm{H}$ ead direction cells are in fact sensitive to directional cues (AT N : G oodridge and Taube, 1995; Knierim et al., 1995; PoS: Taube et al., 1990b; Goodridge and Taube, 1995; LD N : M izumori and Williams, 1993; parietal and cingulate cortex: Chen et al., 1994b; Chen et al., 1994a). Blair and Sharp (1995b) have shown that head direction cells in AT N are influenced by both vestibular and visual motion cues (like place cells, above). When head direction cells and place cells are recorded simultaneously, they have been found to rotate in correspondence ( $\mathrm{MCN}$ aughton et al., 1994a; Knierim et al., 1995).

There are differences between the various head direction areas which we can use to narrow down the possible roles cells in each area might play. Although AT N and POS H D cells are sensitive to rotation of a cue card (Goodridge and Taube, 1995; Taube et al., 1990b), they do not require visual input to show a strong directional signal. If a rat is brought into a maze in the dark, the head direction is carried over from its previous environment, most likely by vestibular input, but probably also by motor efferent information if available (Goodridge and Taube, 1995). Although the two populations seem similar, Blair and Sharp (1995a) and Taube and Muller (1995) have recently shown a difference between them: ATN cell activity is best correlated not with current head direction, but with head direction approximately 20-40 msec in the future. PoS head direction cells, on the other hand, are best correlated with the animal's current (or recent ${ }^{5}$ ) head direction.

AT N and PoS are interconnected (van Groen and Wyss, 1990). Lesions to ATN cause a disruption of directional selectivity in the PoS head direction population (G oodridge and Taube, 1994). The reverse does not appear to be true, which suggests that AT N may be the source of the POS head direction signal (Taube and M uller, 1995). Although LDN is interconnected with PoS (van Groen and Wyss, 1990), lesions to LDN do not disrupt directional selectivity in PoS head direction cells (Golob and Taube, 1994).

${ }^{5}$ Both Blair and Sharp (1995a) and Taube and M uller (1995) report an optimal correlation of ATN activity with future head direction and PoS activity with current head direction, but Blair and Sharp (personal communication) have recently revised their estimates, suggesting that although ATN activity still anticipates future head direction (by $24 \mathrm{msec}$ ), PoS activity may lag the current head direction (by $13 \mathrm{msec}$ ). 
There are no published data on how LDN lesions affect ATN cells.

Although head direction cells in LDN are not sensitive to movement of single cues, they are dependent on visual input. If the rat is placed into the arena in the dark, the cells do not show a strong head direction signal (M izumori and Williams, 1993). After a 30 -second exposure to light, $47 \%$ of the head direction cells showed direction-selective firing, and after 60 seconds, all of them did. If the lights are turned off after the rat has been exposed to the maze in the light, the directional firing persists, but begins to drift after 2 to 3 minutes (M izumori and Williams, 1993).

The parietal cortex (also known as area 7 of Krieg, 1946, and Oc2M of Zilles, 1985) is tightly coupled to the LDN; the posterior cingulate cortex (also known as retrosplenial cortex, areas Rdg and Rga/b in Figure 3) is tightly coupled to the postsubiculum and other parts of the subicular complex (pre and parasubiculum) (van Groen and Wyss, 1990; Wyss and van Groen, 1992) as well as the anterior thalamic nuclei (Vogt, 1985; Wyss and van Groen, 1992). Although there are also head direction cells in the both the parietal and posterior cingulate cortices of the rat (Chen et al., 1994b), there were some differences between these cortical head direction cells and the LD N , AT N and PoS head direction cells described above.

$\mathrm{H}$ ead direction cells in the parietal and posterior cingulate cortices tended to show a broader tuning to direction than the triangular function described above (Chen, 1991; Chen et al., 1994a; Chen et al., 1994b). Additionally, head direction cells in parietal cortex showed a strong modulation by motion behavior (Chen et al., 1994a). H D cells in granular retrosplenial cortex did not show the strong behavioral modulation of parietal HD cells, but some cells in the dysgranular retrosplenial cortex did show some behavioral modulation (Chen et al., 1994a).

M ost importantly, however, head direction cells in the parietal and posterior cingulate cortices did not show the clean sensitivity to distal cues reported for ATN and POS head direction cells. (H owever, Chen et al. used large cardboard panels at the ends of four of the arms of the radial maze, while the ATN and POS studies used a cue card in a cylindrical arena.) N onetheless, some cells (24\%) did rotate with the cues, but most (61\%) did not. And some cells $(15 \%)$ showed tunings to head direction that had multiple peaks during cuemanipulation tasks, that is, they did not show the compact tuning to a single head direction that AT N and PoS cells do. Finally, the proportion of head direction cells in parietal cortex (3\%) and posterior cingulate cortex (8\%) reported by Chen et al. (1994b) is significantly lower than for AT N (56\%: Taube, 1995), PoS (26\%: Taube et al., 1990a), and LDN (51\%: M izumori and W illiams, 1993).

Cells correlated with head direction have also been found in striatum (Wiener, 1993), but in the task used to study striatal head direction cells, a number of other factors such as approach to a corner of the rectangular arena are correlated with head direction. Any of these factors could al so be driving head direction sensitivity. The fact that the directional preferences of these cells rotated with rotation of the arena and were independent of extra-maze room cues and a light which did not rotate with the arena (Wiener, 1993) suggest that these cells are tuned to intra-maze cues. In this task, cells that are peaked to approach of a stimulus (such as a specific corner) will appear as head direction cells. Additionally, only three of 30 cells were classified as head direction cells (W iener, 1993). W iener classified eight of these 30 as place cells and six as tuned to behavioral sequences. When M izumori and Cooper (1995) recorded from striatal head direction cells on the eight-arm radial maze, they found that the head direction sensitivity was not consistent in the dark. Some striatal cells changed their preferred directions suddenly and drastically within a single trial. This has never been observed in the extensive work done on POS, AT N , or LD N reviewed above.

Striatum is more likely to be implicated in taxon navigation ${ }^{6}$ (Potegal, 1982; Abraham et al., 1983; Packard et al., 1991). In the M orris water maze (M orris, 1981), striatal lesions disrupt navigation to cued platforms (such as visible platforms or platforms with a large black card marking the quadrant), not hidden platforms (M CD onald and White, 1994), while postsubiculum lesions disrupt navigation to hidden platforms (Taube et al., 1992). In a plus-maze, hippocampal lesions disrupt place learning, while caudate lesions disrupt response learning (Packard and M CG augh, 1992).

The head direction populations reviewed above are consistent with a hypothesis that 1) PoS head direction cells encode the current head direction and are updated via a loop including AT N (as suggested by Blair and Sharp, 1995a), 2) that LD N cells carry visual input into the system derived, presumably, from distal landmarks, and 3) that parietal and posterior cingulate cortex carry idiothetic information into the system (similar to a suggestion by Chen et al., 1994b). In terms of the components of the head direction subsystem in Figure 2, the representation of current head direction is realized by cells in Postsubiculum while update from visual cuesis realized by LDN and update from vestibular cues by AT N .

This hypothesis predicts that lesions to the LD N should impair POS and AT N sensitivity to distal landmarks and that parietal and posterior cingulate cortex lesions should disrupt the AT N and PoS sensitivity to self-motion cues. Additionally, examining whether head direction cells in parietal and posterior cingulate cortex and in LD N are tuned to current or future head direction (as Blair and Sharp, 1995a, and Taube and M uller, 1995, have done for AT N and PoS) should be very interesting.

\section{Anatomy of the Path Integrator}

We made a lengthy diversion into the head direction system because the path integrator requires direction of motion information (closely correlated to head direction) in order to update the vector representing the animal's location. ${ }^{7}$ We now consider the

${ }^{6}$ Taxon navigation is defined by 0 'Keefe and Nadel (1978) as including both routes and guidances. It can be implemented by stimulus-response mechanisms using cues from single landmarks. ${ }^{7}$ Although head direction is correlated with direction of motion, animals can obviously travel in directions they are not facing. It is not clear how the path integration system handles motion in a different direction than the animal's heading. O ne possibility is that there is an override mechanism which updates the path integrator correctly; alternatively, the path integrator might produce incorrect results. 
question of where path integration might be accomplished in the rodent brain. The regions that implement this function must collectively satisfy the following requirements: 1) receive input from the head direction system; 2) send output to an area associated with the place code; 3) show activity patterns correlated with the position of the animal, 4) receive information about self-motion from the motor and vestibular systems; and 5) update the position representation using self-motion cues.

M cN aughton and N adel (1990) and M cN aughton et al. (1996) suggest that the key to a rodent's ability to path integrate lies in the hippocampus. The place cell representation in hippocampus forms a basis set (such as used in Pouget and Sejnowski, 1995), and so any function of location can be approximated by a linear combination of place cell activities. This includes the position update function computed by a path integrator. H owever, because each environment is represented by a different active subset of place cells (Thompson and Best, 1989), the weights to synthesize an update function from a linear combination of active place units would have to be learned separately for each environment.

Sharp (1995) suggests the subiculum as the locus of the path integrator because subicular place cells show similar place fields across different environments. This suggests that the subiculum can meet criterion 5: because each environment is represented by the same subset of place cells, only one update function has to be learned for all environments. The subiculum also meetscriterion 1: Sharp and Green (1994) report that subicular cells show a directional signal. And it meets criterion 3: the activity of subicular cells constitutes a representation of position in the environment. However, the subiculum does not send output directly to the place code; its output is to deep, not superficial entorhinal cortex (Kohler, 1986; Kohler, 1988). Nor does the subiculum receive input from the motor system, though it does receive input from hippocampus, and hippocampal cells are sensitive to vestibular inputs (Sharp, 1995).

We suggest that path integration is accomplished by a loop composed of the hippocampus, the subiculum, the parasubiculum, and the superficial layers of the entorhinal cortex. Taube (1996) reports place cells in the parasubiculum. However, only $10 \%$ of the cells fit the characteristics of place cells and there were some statistically significant differences between parasubicular and hippocampal place cells. Parasubicular cells have larger place fields and carry less information per spike ${ }^{8}$ than hippocampal cells, but like hippocampal place cells, they are sensitive to rotation of sensory cues, such as a cue card taped to the wall of the arena. It is not known whether parasubicular cells are sensitive to different environments or to surfaces (as hippocampal cells are, but subicular and entorhinal cells are not; see above). It is not clear yet whether these findings support the hypothesis that the parasubiculum is part of the path integrator, but they do suggest that it is part of the navigation system.

The parasubiculum also sends output directly into the superior layers of the entorhinal cortex, bypassing the deep layers (Kohler, 1986; Kohler, 1988; van Groen and Wyss, 1990; Wyss and van Groen, 1992). If the path integrator does involve the parasubicu-

${ }^{8}$ See (Skaggs et al., 1993) for measurement methodology. lum, then path integration information should have entered the hippocampal place code as early as sup-EC. This is compatible with our previous suggestion that sup-EC place cells should be understood to be part of the place code (see above, Sensory C ues: Local View).

This hypothesis leads to three predictions. First, place cells in parasubiculum should not be sensitive to environment (similar to sup-EC and subicular place cells). Second, place cells recorded from sup-EC, parasubiculum, and subiculum should all continue to show place fields in the dark just as CA3 and CA1 place cells do. EC cells are not sensitive to cue card removal (Q uirk et al., 1992), but no experiments have been reported examining EC, parasubicular, or subicular cell activity in the absence of visual input. Third, lesions to subiculum or parasubiculum should disrupt place cell firing in the dark.

A study by Miller and Best (1980) recording from place cells with EC lesions would seem to disprove this hypothesis because even with bilateral EC lesions, place cells were still present in hippocampus. This would seem to imply that the place cells in hippocampus can show place fields even without EC (which would support the hippocampus as path integrator theory above), but almost half of the cells recorded from the lesioned animals were not place cells (compared with $100 \%$ place cells in control animals). In addition, the place cells that were intact were not sensitive to distal cues, only to local ones.

It is not clear what local cues were being used by the rats in the M iller and Best study. Even if the hippocampus serves as the path integrator, in order for the place cells to be consistent across sessions, the rats must have re-initialized their place code upon reentry into the environment (see below, Familiar Environments). W ith no sensory cues entering from entorhinal cortex, the animals could not have aligned their place code. We are not qualified to judge the completeness of the lesions made by M iller and Best, but suggest that the most likely explanation is a partial sparing of EC.

M izumori et al. (1992) inactivated the septal regions with tetracaine and found that the average place specificity of sup-EC cells decreased significantly during the inactivation, but that the average place specificity of deep-EC cells was unchanged. M izumori et al. also found that CA1 place fields were mostly unchanged. This would seem to support the hippocampus as path integrator theory, but in actuality, it only supports the suggestion that the hippocampus can "clean up" the signal from sup-EC, compatible with the suggestions of M arr (1969), M cN aughton and M orris (1987), and Rolls (1989). See below, Novel Environments.

The posterior cingulate cortex, also called retrosplenial cortex (areas Rdg and Rga/b in Figure 3), may also play a role in path integration. Postsubiculum, a major component of the head direction system, is interconnected with the posterior cingulate cortex (van Groen and Wyss, 1990; Wyss and van Groen, 1992). And neurons sensitive to direction of motion, speed, and turning angle are present in posterior parietal cortex ( $\mathrm{M} \mathrm{cN}$ aughton et al., 1994b; Chen et al., 1994b) which is reciprocally connected to posterior cingulate cortex (Chen et al., 1994a; Chen et al., 1994b). 
Posterior cingulate lesions disrupt learning in the M orris water maze (Sutherland et al., 1988; Sutherland and Rodriguez, 1990), but these results are based on aspiration lesions, and it has been suggested ( $N$ eave et al., 1994) that the spatial impairments are from damage to the cingulum bundle, a fiber tract connecting the anterior thalamic nuclei and the hippocampal formation but passing through cingulate cortex. It is not known whether lesions that spare fibers-of-passage will al so disrupt learning in the M orris water maze, but cytotoxic lesions that spared the cingulum bundle did not produce impairments in other spatial tasks ( $N$ eave et al., 1994). Sutherland and H oesing (1993) report data suggesting that cingulate cortex is as crucial as hippocampus for navigation: they show that unilateral hippocampal lesions paired with opposite hemisphere unilateral posterior cingulate lesions are as devastating as bilateral hippocampal or bilateral cingulate lesions.

We have suggested that path integration in the rodent is accomplished by a loop including the hippocampus, the subiculum, the parasubiculum, and the superior layers of the entorhinal cortex. This hypothesis meets all five of our criteria: 1) The parasubiculum receives input from the postsubiculum, which represents the current head direction. 2) The place code is in the hippocampus and is therefore incorporated into the path integration mechanism. 3) The place like cells in all four major structures can represent the position of the animal. 4) Information about the motion of the animal can enter the system from the parietal and cingulate cortices, via their projections to the parasubiculum. 5) As suggested by Sharp (1995), Samsonovich and M CN aughton (1995), and M CN aughton et al. (1996), place-like cells can update their position using 2D attractor representations given sufficient offset connections.

This hypothesis makes a number of predictions. For example, lesions to any of these structures should produce path integration deficits. It also means that there should be representations of the rodent's location in each of these structures and that these representations must be valid even in the absence of visual cues, as in the dark.

\section{REFERENCE FRAMES}

In this section we review data on place code changes that occur not only across environments, but across tasks within an environment and stages within a task. We suggest that rodents represent their position within reference frames that are goal or task dependent, and that is why different tasks or stages of a task are represented using different place codes. A reference frame has three components. A reference point that serves as the origin for path integration, and a canonical orientation with respect to which heading is encoded by the head direction system, together define a coordinate system. Third, a mental set derived from the goals or activities associated with this coordinate system labels the reference frame so that it can be distinguished from others.

A single coordinate system encompassing the entire world is implausible, because it would require path integration over arbitrarily large distances, and because the space of coordinate values representable in the path integrator would have to be very large. In the case of a vector representation as in (Touretzky et al., 1993), the number of discriminable vector magnitudes, encoded as firing rates across a population, becomes too great. For representations based on a moving hill of activation on a 2D sheet of cells as in (Samsonovich and M CN aughton, 1995), too many cells are required. Thus, rodents must be using different reference frames, represented over the same set of units, to encode different environments.

Because place cells make use of path integrator information, they must be sensitive to the choice of reference frame. A change in reference frame could therefore be experimentally observed as a change in the active subset of place cells (Wan et al., 1994b; Touretzky and Redish, 1996).

W hen rats were trained to search for food on a large elevated platform either randomly or at the corners of a diamond, different subsets of place cells were active for each task, and some cells that were active for both tasks had different place fields, as if the animals were encoding the tasks as two different environments ( $M$ arkus et al., 1995). When the animal switched between these two tasks, the change between representations was rapid, suggesting a shift in a property encompassing the entire system, such as reference frame. $M$ arkus et al. found some cells with similar fields in both environments, suggesting that there are two levels of representation here: the physical environment and the task within the environment. This does not imply, however, that there are two simultaneously active reference frames. Since the two tasks are occurring in the same environment, some cells may be tuned to the same cues in both tasks.

In more complex tasks than simply finding food scattered on the floor of the arena, place cells do not always fire when the animal is in the place field. Eichenbaum et al. (1987) tested rats in an odor-detection task and found that some place cells were dependent on whether the rat had al ready sampled the odor, while other cells were dependent on whether the rat was going to the reward location. In a similar task, 0 tto and Eichenbaum (1992) found that cells responded when two odors matched in a delayed-match-to-sample task, but not when they didn't. H ampson et al. (1993) tested rats in a multiple lever-pressing delayedmatch-to-sampletask and found place cells dependent on whether a lever had already been pressed or not. These results are compatible with the hypothesis that each stage is encoded by a different reference frame, presumably centered on the goal of that stage of the task.

Bostock et al. (1991) recorded from place cells in an open cylindrical arena, first with a white cue card, and then with a black cue card. Sometimes the place fields were similar and sometimes they were unrelated (as if the two situations were encoded as different environments). However, once a place field changed dramatically between the two cue cards then 1) all other place fields recorded from the same animal changed dramatically when the environment included the black cue card and 2) when the white cue card was returned the place fields returned to their original configuration. Similar effects have been reported by Q uirk et al. (1990) and Sharp et al. (1995). We suggest that at 
some point the animals began to encode the black cue card trials with a new reference frame.

On linear tracks, or arms of a radial maze, some place cells are dependent on the direction of travel as well as location ( $\mathrm{M} \mathrm{CN}$ aughton et al., 1983a). These directional place cells can also be understood as being tuned to stages of the task: traversing the track leftward versus rightward (or inward versus outward on a radial maze) can be thought of as distinct subtasks. A larger proportion of place cells show tuning to direction in tasks with restricted trajectories than in tasks with unrestricted trajectories (M uller et al., 1994; M arkus et al., 1995).

Directionality on a narrow track or with restricted trajectories can be explained by assuming that the animal has two reference frames, and only one of these is active on each trajectory. A place cell tuned to one reference frame and not the other will only fire when the rat runs in one direction along the track (Wan et al., 1994b). A similar suggestion has been made by $M$ arkus et al. (1995) and M CN aughton et al. (1996).

$\mathrm{H}$ ow reference frames are encoded in the brain is unclear. Some insight may be gained by examining place and head direction cell activity in situations with conflicting reference frames. A few such experiments have been done (head direction cells in a cue-conflict situation: Goodridge and Taube, 1995; Taube and Burton, 1995; Blair and Sharp, 1995b; place cells in a cue-conflict situation: Sharp et al., 1995, and place cells in an environment with cues that vary independently: 0 'K eefe and Conway, 1978; M iller and Best, 1980; Shapiro et al., 1989; G othard et al., 1995; G othard et al., 1996).

\section{Relationship to Other Theories of Navigation}

In the original formulation of the cognitive map hypothesis ( 0 'Keefe and $\mathrm{N}$ adel, 1978), one of the key differences between locale and taxon navigation was that the former occurrs with respect to a single cue, while the latter involves constellations of cues. $\mathrm{O}$ 'K eefe and $\mathrm{N}$ adel pointed out that this meant the cognitive map had to be internally consistent: If the animal learned a cognitive map relative to a constellation of cues and then some of those cues moved while others did not, the map should tend to rigidly translate and/or rotate to follow some consistent subset of the cues. The concept of reference frames is an extension of this hypothesis, making the cognitive map hypothesis concrete enough to be applied to specific instances (such as to explain taskdependent place cells, above).

M cN aughton et al. (1996) have recently suggested that the rodent hippocampus contains subpopulations of cells interconnected so that 1) cells are more likely to be connected within a population than between populations and 2) cells within a population that have nearby place fields are preferentially interconnected. They call each subpopulation a "chart" and suggest that different environments would be encoded by different charts. A single cell could belong to many charts; the chart it was participating in at a given moment would depend on the cells that were coactive with it.
Both reference frames and charts can explain the observations of M uller and Kubie (1987) and Thompson and Best (1989) that different environments are encoded by different subsets of place cells in CA3/CA1. But charts are an architecture specific to CA3/CA1, whereas reference frames are a system-level property arising from an interaction between the head direction and path integration systems. It is possible that some aspects of reference frames are implemented by charts, but system-level issues such as deciding when to switch reference frames or when to create a new one are not easily addressed at that level.

A number of authors (M uller et al., 1991a; M cN aughton et al., 1994a; $M$ arkus et al., 1995) have suggested that some of the sensitivity of place cells to cues other than visible landmarks can be attributed to changes in attention to "virtual" landmarks. These are locations in space from which distance and bearing information can be derived, just like for real landmarks. H owever, since they're not tied to perceivable objects, instead of being tracked by the perceptual system virtual landmarks must be tracked by path integration. Although a reference frame could be said to employ a virtual landmark as its reference point, reference frames also include a canonical orientation, so the two proposals are not equivalent. Just as no one has suggested a limit on the number of real landmarks the rodent perceptual system can handle, the virtual landmark proposals have placed no limit on the number of virtual landmarks that can be tracked at once.

\section{How Many Reference Frames Can Be Active Simultaneously?}

Because the animal has only one path integrator and one head direction code, it should only be able to represent a single reference frame. The evidence we review bel ow suggests that this is the case: rodents only operate in one reference frame at a time.

Gothard et al. (1996) trained rats to find food relative to a pair of landmarks which were moved with each trial. The two landmarks were not moved relative to each other, i.e. they al ways had the same spatial relationship to each other. In this experiment, the animals began from a start box which was also moved independently of the room and of the landmarks with each trial. This defined three independent reference frames: a "room" frame, a "goal" frame, and a "box" frame. Gothard et al. found different subsets of place cells tuned to each reference frame and found that only one reference frame was active at a time. Cells tuned to the box frame were not active except when the animal was in, entering, or leaving the box; cells tuned to the goal frame were only active near the goal. At other times, cells tuned to the room frame were active.

Gothard et al. (1995) tested rats on a linear track with a box placed on the track. In addition to the normal place cells with place fields related to position on the track ("track" cells), they found cells that fired when the animal was in the box ("box" cells). When the box was placed over a track cell's field, the track cell was silent, but the box cells were strongly active. This implies that only one of the two reference frames was active at any time. 
Even with this limitation, an animal must still be able to relate two reference frames in order to transition from one environment to another. Whether this requires the ability to have the two simultaneously active is an open question.

\section{Is the Separation of Reference Frames Internal or External to the Hippocampus?}

The data suggesting that hippocampal place cells are sensitive to reference frame imply that there must be some mechanism enabling these cells to detect the reference frame. 0 ne possibility is that a reference frame signal enters the hippocampus via a path other than the perforant path from EC. The alternative is that reference frame information is present in the EC signal, but is masked by a stronger location signal that is independent of reference frame.

The data of Q uirk et al. (1992) that entorhinal place cells are not sensitive to the differences between similar environments suggest that EC place cells are not sensitive to reference frame. H owever, M izumori et al. (1992) report that EC cells are sensitive to direction on linear trajectories (on an eight-arm radial maze) which implies that they are sensitive to reference frame. The second hypothesis could explain this discrepancy if the reference frame signal in the EC cells in Quirk et al.'s study was overwhelmed by the similarity in the local views in the two environments. This explanation is also compatible with proposals by $M$ arr (1969), Rolls (1989) and $O$ 'Reilly and McClelland (1994) that the dentate gyrus pulls apart patterns that are similar in EC; hence a weak EC reference frame signal could produce highly distinct place codes in CA3/CA1.

On the other hand, if the first hypothesis were true, the reference frame signal would have to enter the hippocampus via a different fiber tract than the perforant path. In addition to input from EC, the hippocampus receives subcortical input via the fimbria. Lesions to the fimbria that spare the fornix produce behavioral deficits when changing goals ( $\mathrm{M}$ ' $\mathrm{H}$ arzi et al., 1987).

M iller and Best (1980) and Shapiro et al. (1989) report data on place cell activity on a radial maze after rotation in animals with and without fimbria/fornix lesions. Normal place cells always showed the same place field with respect to room cues (i.e. their place fields did not rotate with the maze), but after the lesion, half of the place fields rotated and half did not (M iller and Best, 1980).

Rotation of the radial maze makes the intra-maze cues inconsistent with the room cues. Because the place cells in this study were not recorded simultaneously, we cannot determine whether the reference frame selection mechanisms were more likely to follow the intra-maze frame over the extra-maze frame after the lesion or whether the mechanisms that ensure that the place code works within a single reference frame had actually broken down. However, it is clear that fimbria/fornix lesions have a profound effect on reference frame choice.

Although these experiments suggest that the reference frame signal enters the hippocampus via the fimbria, it is also possible that the fimbria input is necessary for the intra-hippocampal separation of perforant path-defined reference frames. (See below, $N$ ovel Environments, for a discussion of cholinergic input and its effect on hippocampus.) It would be interesting to compare recordings from cells in the septal nuclei (the main source of the fimbria) with the rat in different environments or performing different tasks. We are not aware of any such recordings in rodents.

\section{FROM PLACE CODES TO ACTION}

If place cells are used in spatial navigation, rodents must have a means of combining place information with information about current goals to generate motor actions. This is the task addressed by the final subsystem in Figure 2: the goal subsystem.

The nucleus accumbens is one of the major targets of the fornix (Witter et al., 1990), which carries place information from subiculum and CA1. We suggest that the nucleus accumbens maintains an association between locations, goals, and actions. By combining spatial information about the animal's current location from the hippocampus and subiculum with emotional information about the animal's current desires and drives from the hypothalamus and amygdala, the accumbens can generate motor actions that would lead to satisfying the goal. A similar suggestion has been made by Brown and Sharp (1995).

The amygdala and hypothalamus have been implicated in emotion and goal information by a number of studies. (See Aggleton, 1993; D avis et al., 1994, for reviews.) The nucleus accumbens receives afferent fibers from amygdala (Aggleton, 1993; D avis et al., 1994), from the ventral tegmental area (Wolske et al., 1993), and from the hypothalamus (Domesick, 1981). Additional studies have implicated the nucleus accumbens as a locomotor area (Jones and Mogenson, 1980; M ogenson, 1984; M ogenson and N ielsen, 1984).

Lavoie and Mizumori (1994) recorded single neurons from nucleus accumbens as rats performed a radial maze task. They found cells with firing rates correlated with task-specific variables such as place, reward, and movement. Kiyatkin and Gratton (1994) have shown that dopaminelevels in nucleus accumbens are related to motivation and reward. In a lever-pressing task, Kiyatkin and Gratton found that dopamine levels in accumbens increased before the first lever press, fell at the lever press, and then rose again until the next lever-press. The amount by which the dopamine level fell was correlated with the amount of food that appeared at the lever press. Wickens and Kotter (1995) review data showing that the injection of dopamine into the accumbens can produce conditioning similar to natural rewards, as can direct stimulation of dopaminergic neurons. Dopamine antagonists attenuate the effects of this stimulation. Wickens and Kotter also review data showing that dopamine neurons are activated by natural rewards. Although we hesitate to identify dopamine level with motivation, this data clearly demonstrates that dopamine levels in accumbens are related to motivation and reward.

W hishaw and M ittleman (1991) have shown that the nucleus accumbens and the caudate and putamen are counter-balanced to control locomotor and stereotyped behavior, and that the hippocampus mediates locomotor activity through the nucleus accum- 
bens. H ippocampal lesions produce an excess of locomotor activity (Isaacson, 1974), but adding a lesion to nucleus accumbens abolishes this activity (W hishaw and M ittleman, 1991). Hippocampal lesions combined with caudate and putamen lesions produce extreme excesses of locomotor activity (W hishaw and M ittleman, 1991).

Lesions of the nucleus accumbens produce difficulties in spatial discriminations, and impair learning the Morris water maze (Annett et al., 1989). Although rats in the M orris water maze did spend more time in the correct quadrant than chance, their best runs were still impaired compared to normals (Annett et al., 1989). Sutherland and Rodriguez (1990) report that naive rats with lesions to the nucleus accumbens were impaired by measures of latency and quadrant preference compared to normals, but that there were no significant effects with visible platforms or pretrained rats.

The fact that there was little effect of accumbens lesions on pretrained rats implies that the accumbens cannot be the only pathway by which the place code can drive locomotor activity. An alternative pathway could be from CA1 and subiculum to deep layers of EC and then back to the cortex. $\mathrm{D}$ ata from $\mathrm{N}$ ilsson et al. (1987), below, also suggests the existence of an alternate pathway: rats with fimbria/fornix lesions and septal grafts showed an ability to relearn place locations. Sutherland and H oesing (1993) suggest that the pathway is back through posterior cingulate cortex.

W hishaw et al. (1995) report that if fimbria/fornix-lesioned rats are trained to swim to a visible platform in the M orris water maze, then they show normal place learning of that visible target (i.e., when the visible target is removed, they swim to its former location). On the other hand, they cannot learn to swim to a hidden target. This result is compatible with our hypothesis that the fornix carries location information from the place code (in hippocampus and subiculum) to the nucleus accumbens, but that there are other weaker pathways that may require additional information to instantiate, such as would be provided by a visible target.

This hypothesis also implies that subicular lesions should have devastating effects on trajectory planning. M orris et al. (1990) found that subicular lesions impair performance in the $M$ orris water maze as much as hippocampal lesions do, as do fornix lesions (Eichenbaum et al., 1990; Sutherland and Rodriguez, 1990). H owever, the effect of subicular lesions on performance in the M orris water maze is very different from that of hippocampal lesions (M orris et al., 1990). Animals with hippocampal lesions swim in stereotyped circles at the correct distance from the wall; animals with subicular lesions search for the goal like naive rats. Unlike hippocampal rats, who swim the same path over and over again, subicular animals rarely repeat the same path segment. This suggests that hippocampal rats are unable to determine their own location, even though they may know facts about the goal location (its distance from the wall, for example), but that subicular rats have lost all knowledge of the goal location.

Although there is evidence that the accumbens is not the only means by which the goal subsystem can plan trajectories, we have reviewed substantial evidence that it plays a key role in planning trajectories and actions given information in the place code.

\section{INTERACTIONS WITH THE ENVIRONMENT}

We now turn from the requirements for a locale navigation system to the question of how such a system interacts with the environment. We first examine what the system must do to recognize a novel environment. Then we examine how the four main subsystems (place code, local view, path integrator, head direction code) are kept aligned with each other and with their values on previous encounters with a familiar environment.

\section{Novel Environments}

$\mathrm{H}$ ow do rodents recognize a novel environment? 0 ne factor is likely to be the geometric structure of the arena (G allistel, 1990). Place cells in CA3 and CA1 are sensitive to arena geometry (Muller and Kubie, 1987), but place cells in EC and subiculum are not (Q uirk et al., 1992; Sharp, 1995). Rodents are also sensitive to configurations of cues (Suzuki et al., 1980), as are CA3 and CA1 place cells (O 'Keefe and Conway, 1978; O 'K eefe and Speakman, 1987; Pico et al., 1985). Although there are a number of studies showing that perturbation of visual landmarks can trigger exploration (Poucet et al., 1986; T hinus-Blanc et al., 1987; Thinus-Blanc et al., 1991; Thinus-Blanc et al., 1992), and how agonists or antagonists of specific neurotransmitters affect exploration (Buhot and Naili, 1995), no computational models of environmental recognition have been proposed.

An animal that treated an environment as novel whenever a single cue was missing or repositioned would never see a familiar environment. $\mathrm{O}$ the other hand, if enough has changed that the environment really is novel, the animal will be best served by treating all of the cues it sees as novel as well. This issue can be phrased in terms of completion and separation: Sensory information from each environment is assumed to be represented as a distributed pattern of activity over a population of cells. Above some threshold of overlap of the current representation with a remembered representation, the animal will want to complete the new representation based on the old, while below that threshold, the animal will want to separate the two representations as much as possible to prevent memory interference.

This is discussed by O'Reilly and McClelland (1994), who suggest the dentate gyrus is well suited for separation and CA3 for completion. M arr (1969) and Rolls (1989) made similar suggestions that D G separates inputs from EC into orthogonal representations, while the recurrent collaterals in CA 3 form an associative memory (Kohonen, 1977; Kohonen, 1980) to complete input representations. It has been shown that $D G$ is required for learning spatial tasks, but not for their performance, and that removal of DG does not change already learned place cells (M cN aughton et al., 1989).

In addition to glutamatergic input from EC, the hippocampus receives cholinergic input from the septal nuclei (Cooper et al., 1986; H asselmo and Bower, 1993; M izumori et al., 1992; Stewart and Fox, 1990), serotonergic input from the raphe nucleus (Cooper et al., 1986), and noradrenergic input from the locus 
coeruleus (Cooper et al., 1986). These neuromodulatory inputs have been implicated in the recognition of novel environments and detection of changes in familiar environments. Although we review key details relating acetylcholine and serotonin to the recognition of novelty and changes in environments, we do not review the general cellular effects of these or other neuromodulators because these effects have al ready been extensively reviewed by $\mathrm{H}$ asselmo (1995).

\section{Acetylcholine}

When learning a new environment, the recurrent connections within CA3 will still drive the new representation towards an al ready stored one. This will cause interference between the two representations (H asselmo, 1993; H asselmo and Bower, 1993). $\mathrm{H}$ asselmo and Schnell (1994) have shown that in CA1, acetylcholine $(\mathrm{ACh})$ reduces the effect of the Schaffer collaterals by $90 \%$, but affects the perforant path much less. Since the Schaffer collaterals are the same axons which form the CA3 excitatory feedback pathway, this suggests that ACh may shut off these recurrent connections. Returning to the conceptual framework suggested above, $\mathrm{H}$ asselmo and Schnell's hypothesis is that $\mathrm{AC} h$ turns off the pattern completion process. ACh enhances LTP in D G , and although it suppresses transmission, it also enhances LT P in the Schaffer collaterals (H asselmo, 1995). The results from M izumori et al. (1992) that with septal inactivation, the average specificity of sup-EC place cells decreases but that of deep-EC cells does not change (reviewed above, see Anatomy of the Path Integrator) support this dichotomy. With septal inactivation, there would be low ACh in the hippocampus and the recurrent connections in CA3 could still refine the low place specificity of the sup-EC cells by the completion process described above. Projections from CA1 to deep-EC would keep the specificity of deep-EC cells from changing.

Inactivation of the hippocampal septal input impairs learning spatial tasks (M izumori et al., 1990). A tropine sulfate (a muscarinic $\mathrm{ACh}$ blocker) impairs learning of the M orris water maze (Sutherland et al., 1982), however, Sutherland et al.'s rats were only tested for a week. When the rats were tested for a month, they did eventually learn a spatial strategy for the task (W hishaw, 1985). Whishaw also showed that atropine given to rats who had learned the task had no significant effect; the animals showed no differences in cued navigation, except that atropine rats reared more than normals.

$\mathrm{Nilsson}$ et al. (1987) showed that performance deficits in the $M$ orris water maze produced by lesions of the fimbria and fornix could be reversed by restoring $\mathrm{ACh}$ throughout hippocampus. This was done by grafting fetal rat septal tissue into the septal regions of the lesioned rat. They found that fimbria/fornix transection disrupted spatial learning and memory in both naive and pretrained rats, that grafting fetal septal tissue restored the ability to use spatial cues, and that atropine disrupted the spatial ability restored by the graft.

This implies that the $\mathrm{ACh}$ fibers from the septal regions are only transmitting a scalar quantity, i.e. the identities of individual fibers are not important. 0 therwise, since the grafted neurons would not have the same connections as those destroyed by the lesion, the graft could not have restored the animals' spatial ability. An alternative hypothesis is that the animals relearned the task with the new connections. H owever, the speed with which the rats re-acquired the task suggests that the graft restores the old memories. These two hypotheses could be tested by comparing the ability of rats with grafts to learn new versus old platform locations.

Shapiro et al. (1989) studied place cells in normal rats, in rats with lesions to the fimbria/fornix (lacking $A C h$ ), and in rats with fetal basal forebrain tissue grafted in (with ACh restored). Their results are compatible with the suggestion that $A C h$ reduces the effect of pattern completion interference in CA3. They recorded from place cells in a radial arm maze and then examined the effect of rotating the maze. When the maze is rotated, a decision must be made whether to follow the local or distal cues which are now in conflict. (See above, Reference Frames.)

Shapiro et al. (1989) found that place cells in fimbria/fornixlesioned rats followed local cues, but were still partially influenced by distal cues, as evidenced by the lower reliability of place fields in lesioned rats during rotated trials. In rats with grafts, place fields followed distal cues and were more reliable and more compact than those of lesioned rats without grafts. We suggest that the representations of place based on local and distal cues interfered with each other, and that the grafts partially restored the rats' ability to separate these reference frames.

W ith low acetylcholine, pattern completion in CA3 cannot be turned off. Thus the place code will try to complete the inconsistent cues (rotated intra-maze and unrotated room cues) with the original reference frame (unrotated intra maze and room cues). Because LTP occurs even at low acetylcholine levels (H asselmo and Schnell, 1994), there will be learning and there will be interference between the two reference frames. Restoring acetylcholine via the grafts should allow the pattern completion in CA3 to be shut off and thus decrease the interference.

Buhot and $\mathrm{N}$ aili (1995) found that rats showed normal habituation to an environment (measured as a function of locomotor activity) under scopolomine (a muscarinic cholinergic antagonist), although scopolomine produced a general increase in locomotor activity compared to normals. H owever, rats injected with scopolomine could only recognize major changes to an environment. Adding objects to an empty environment produced exploration, but displacing one object or replacing one object with a dissimilar one did not. This is compatible with the suggestion that low levels of $\mathrm{ACh}$ produce interference between similar environments (H asselmo, 1993; $H$ asselmo and Schnell, 1994, above).

\section{Serotonin}

Buhot and $\mathrm{N}$ aili (1995) report data suggesting that serotonergic agonists signal familiar environments and changes to those environments. In particular, CP-93,129 (a 5-H T 1B agonist) produced a drastic decrease in locomotor activity early in the experiment. The animals injected with CP-93,129 did not habituate to the empty arena because they treated the environ- 
ment as familiar from the time they entered it. This implies that CP-93,129 impairs the recognition of a novel environment.

Both rats injected with 8-O H -D PAT (a 5-H T 1A agonist) and rats injected with CP-93,129 were able to recognize changes to objects and spent more time with novel or repositioned objects. $\mathrm{H}$ owever, they spent less time than normal animals exploring the changed objects. Again, they did not habituate to this change. Their reaction to the new environments implies that they could recognize novelty, but that it was more difficult for them than for normals.

In direct support of this hypothesis, Crino et al. (1993) reviews data showing that cells in the raphe nucleus (supplying serotonin) increase their firing in the presence of novel stimuli.

\section{Summary}

Acetylcholine seems to be necessary to separate similar environments (and perhaps reference frames). This predicts that intrahippocampal injections of atropine or other cholinergic antagonists should strongly affect place cells dependent on task or stage of task. For example, cholinergic antagonists should affect place cells in animals trained to do multiple tasks within a single environment as in (M arkus et al., 1995) more than animals that have learned only a single task.

The roles of serotonin and norepinephrine (the latter supplied by the locus coeruleus) are less clear. Although complex, the most telling experiments for these questions are those combining serotonergic or noradrenergic lesions, either by injection of antagonists or lesions of the necessary subcortical areas, with place cell recordings.

\section{Familiar Environments}

If the pieces of the locale navigation system are to work together succesfully, they must operate within the same reference frame. ${ }^{9}$ Therefore, once an animal has decided that an environment is familiar, it must align its place, head direction, and path integrator systems, preferably with its memory of past experience in the environment as well as with each other. $N$ europhysiological evidence supports this: both place cells and head direction cells are sensitive to visual cues, and when recorded simultaneously, they al ways rotate in synchrony ( $M$ cN aughton et al., 1994a; Knierim et al., 1995).

\section{Enforcing coherency in the place code}

The first step in ensuring that the system works as an integrated whole is to ensure that the place code is representing a single location within the environment. We say that the place code is coherent if all active place cells have overlapping fields in that environment (Touretzky and Redish, 1996; Redish and Touretzky, 1996). We briefly describe a possible mechanism to enforce

\footnotetext{
${ }^{9}$ As pointed out above, this is analogous to the original requirement of the cognitive map hypothesis (O 'Keefe and N adel, 1978) that the cognitive map be internally consistent.
}

coherency in the place code by parallel relaxation. ${ }^{10} \mathrm{~T}$ his mechanism is discussed in more detail in (Touretzky and Redish, 1996; Redish and Touretzky, 1996). ${ }^{11}$

Upon initial entry into an environment, the place code is instantiated from the local view. But local views can be ambiguous: in a $\mathrm{H}$ ampton C ourt-type maze, for example, some corridors may be visually indistinguisuable from others. And in rotated eight-arm maze experiments, local and distal cues will conflict as a result of the rotation. $\mathrm{H}$ ence, place cells activated by visual input alone can in principle have non-overlapping place fields, making the code incoherent until some corrective process kicks in.

We suggest that a competitive inhibitory process in hippocampus makes the code coherent. This requires 1 ) that place cells with overlapping fields support each other through an excitatory pathway, and 2) that the active place cell population generates inhibitory feedback with little spatial selectivity (essentially a global inhibitory process) to suppress outliers: cells whose place field locations are at odds with the overall consensus about the animal's location. There is evidence that both of these requirements are met in CA3.

LTP has been well demonstrated in the Schaffer collaterals and CA3 recurrent connections (see Landfield and D eadwyler, 1988). Simulations suggest that given $\mathrm{H}$ ebbian learning in the synapses made by the recurrent axons in $\mathrm{CA} 3$, the coupling strength between place cells will be proportional to the distance between their place fields (Muller et al., 1991b; Muller et al., 1995). Supporting this, the timing of action potentials in place cells with overlapping fields are correlated with each other (Wilson and M cN aughton, 1994).

A competitive activation mechanism requires inhibitory feedback. A variety of inhibitory interneurons are known to exist in all stages of hippocampus (Schwartzkroin et al., 1990). Theta cells, for example, are inhibitory interneurons (Ranck, 1973; Fox and Ranck, 1981; Lacaille et al., 1989; Leonard and M CN aughton, 1990). Although they do appear to have some spatial tuning, they have much larger place fields which are much less repeatable between sessions than place fields of pyramidal cells (Kubie et al., 1990; W ilson and M CN aughton, 1994). This should be sufficient to provide the non-spatial inhibitory feedback.

\section{Alignment}

O nce the place code has been made coherent (so it encodes a single location in the environment) the path integrator and head

\footnotetext{
${ }^{10} \mathrm{Anderson}$ and Hinton (1981) explain parallel relaxation as "a constraint-satisfaction paradigm in which some input data must be given an interpretation that simultaneously satisfies a large set of local constraints. This interpretation corresponds to a pattern of activity over the units, and it is found by an iterative computation in which each unit affects many other units until the whole system settles down into a stable state."

${ }^{11}$ In (Touretzky and Redish, 1996), the parallel relaxation occurs by an interaction between the place code and the path integrator. The enforce coherency function in Figure 2 has been placed in the path integrator subsystem to reflect this. In our more recent formulation we show that coherency can be enforced through parallel relaxation within the place code itself.
} 
direction subsystems can be aligned with the place and local view representations. This is the function subserved by the reset and consistency mechanisms in Figure 2. The structure that mediates this alignment must combine location information from the place code (to reset the path integrator) with local view information (so that egocentric direction to local landmarks can be combined with location to reset head direction) and must send projections to each of the other subsystems. The subiculum appears to be a good candidate for this task.

The subiculum receives input from the layer III component of the perforant path (Amaral, 1993; Jones, 1993; Witter, 1993), and from the place code in $\mathrm{CA} 1$, and projects via the fornix to a variety of structures including the nucleus accumbens, the mammillary bodies, and the posterior cingulate cortex (W itter et al., 1990). The subiculum also projects via the angular bundle to deep layers of the entorhinal cortex, as well as the pre, post-, and parasubiculum (W itter et al., 1990). A single subicular neuron can send axonal projections dorsally to cingulate cortex, caudally to entorhinal cortex, and rostrally to the subcortical areas (Finch, 1993).

Sharp and Green (1994) report that subicular cells show a robust location signal, and found that many of the cells were tuned to head direction as well as place. Although direction accounted for only $13 \%$ of the variance, hippocampal place cells rarely show directional tuning in a similar arena (Muller et al., 1994). Another difference between subicular and hippocampal place cells is that subicular place cells show similar responses across different environments (Sharp, 1995; M uller and Kubie, 1987). Sharp suggests that this implies the subiculum is the locus of the path integrator (see Anatomy of the Path Integrator, above), but this result is also compatible with the alignment function we suggest.

This hypothesis makes the prediction that lesions to the subiculum should disrupt the tight coupling of place and head direction cells reported by $\mathrm{MCN}$ aughton et al. (1994a) and Knierim et al. (1995) because the subiculum mediates the alignment of the head direction and place codes.

\section{DISCUSSION}

We have taken the abstract conceptual framework presented in (Touretzky and Redish, 1996) (Fig. 1) and made it concrete on an anatomical level (Fig. 3). We summarize this mapping below.

The place code in the hippocampus depends on a local view subsystem which we have identified with high-level sensory areas in association cortex and the deep layers of entorhinal cortex. The place code is also hypothesized to be dependent on a path integration system, which we suggest is realized by a loop composed of hippocampus, subiculum, parasubiculum, and the superficial layers of EC. This system is in turn dependent on various head direction areas. We suggest that visual cues provided by distal landmarks influence the head direction system via LD N, and that self-motion cues used to update head direction enter the system via parietal and posterior cingulate cortex, which connect to LDN, POS, and ATN. We completed the analysis of interactions between path integration and place code with a discussion of reference frames, which might be subtly represented in EC, but which should exert a greater effect in hippocampus proper under the influence of acetylcholine. Finally, we considered the need for a goal subsystem to formulate trajectories the animal could follow, and suggested it might reside in the nucleus accumbens.

We then explored how this complete locale navigation system should interact with novel and familiar environments. We postulated a mechanism for ensuring that its components remain consistently aligned with each other and with past experience, and assigned this function to subiculum.

One structure we have not included in our theory is the mammillary bodies, which receive a major projection from the fornix (Witter et al., 1990) and in turn project to the anterior thalamic nuclei via the mammillothalamic tract (Bentivoglio et al., 1993). Although there have been a number of lesion studies implicating the mammillary bodies in memory (Jaffard et al., 1991; Sziklas and Petrides, 1993), particularly spatial memory (Sutherland and Rodriguez, 1990), weknow of no neurophysiological studies of mammillary body neurons in behaving animals. Such studies are clearly needed before the role of the mammillary bodies in navigation can be addressed.

\section{Predictions of Our Framework}

O ur framework for a locale navigation system makes a variety of predictions, which we summarize and repeat here. We hope that the experimental community will find some of our suggested experiments sufficiently interesting and feasible to try them.

$\mathrm{H}$ ead direction system. $\mathrm{O}$ ur framework predicts that lesions to the lateral dorsal nucleus of the thalamus should impair postsubicular and anterior thalamic sensitivity to distal landmarks and that lesions to parietal and posterior cingulate cortex should impair AT N and POS sensitivity to self-motion cues.

Path integrator system. O ur suggestion that the parasubiculum and superior entorhinal cortex are part of the path integrator implies 1) that place cells in the parasubiculum should show similar place fields across different environments, as place cells in EC and subiculum do, 2) that place cells in the superficial layers of the entorhinal cortex, parasubiculum, and subiculum should all continue to show place fields in the dark just as CA3 and CA1 place cells do, and 3 ) that lesions to sup-EC, parasubiculum, or subiculum should disrupt place cell firing in the dark.

Alignment. The suggestion that subiculum mediates the alignment of representations on re-entry into a familiar environment predicts that subicular lesions should decouple the place and head direction systems.

Acetylcholine. The suggestion that acetylcholine affects the separation of reference frames predicts that intrahippocampal injections of atropine or other cholinergic antagonists should strongly affect place cells dependent on task or stage 
of task, more so than place cells in animals trained on a single task in a single environment.

The conceptual framework presented here also suggests some experiments that will produce interesting results even though we cannot predict the outcome. We realize that some of these are beyond the scope of current technologies, but we are sure that with the resourcefulness of the experimental community, they will become feasible in the near future.

Is the separation of reference frames internal or external to the hippocampus? We presented two alternative hypotheses for how reference frame information reaches the hippocampus:

1) that there is an extrahippocampal signal that enters the hippocampus via a path that does not involve EC, or 2) that the reference frame signal is present in EC but is masked by a stronger signal indicating location. If the first hypothesis is correct, the fimbria should carry reference frame information. This should be directly observable by recording from the source of the fimbria: the septal nuclei. If the second hypothesis is correct, then across two similar environments there should be a small but significant difference in EC place cell activity.

What is the role of septal neurons in selecting reference frames? Recording from the septal nuclei in animals as they perform different tasks in a single environment or a single task in two different environments could elucidate the role of septal neurons in differentiating tasks and environments.

What istherole of the mammillary bodiesin spatial navigation? The mammillary bodies receive extensive innervation from the subiculum via the fornix and send extensive efferents to the anterior thalamic nuclei via the mammillothalamic tract. Lesion studies have implicated the mammillary bodies in memory, particularly spatial memory. Recording from mammillary body neurons as animals perform spatial memory tasks should produce interesting results.

What is the role of neuromodulators on place cell function? Recording from place cells in free-running animals under the influence of one or more neuromodulatory agonists or antagonists (such as the cholinergic antagonists scopolomine and atropine, or the serotonergic agonists CP-93,129 and 8-O H -D PAT) would help clarify the role these neuromodulators play in navigation.

D o graftsrestore old memories or enablenew ones to form? If the graft studies could be performed on animals with lesioned fimbria but intact fornix, comparing the abilities of animals to learn new platform locations and remember old ones, it could be determined whether the graft restores old memories or re-enables the learning of new ones.

\section{Memory and Navigation}

We now return to the role of the hippocampus in the consolidation of declarative memory. There is extensive evidence that the hippocampal formation is a crucial part of the mechanism for storing declarative memories (facts, episodes, memories of occurrences in space and time). Lesions to the hippocampal formation cause both anterograde and retrograde amnesia in humans and non-human primates. (See Squire and Zola-M organ, 1988, for a review). H owever, the hypothesis that the hippocampus is part of the declarative memory system does not contradict the hypothesis that it is part of the locale navigation system. Extensive work has demonstrated that hippocampal lesions are devastating to the ability to learn and perform tasks such as the Morris water maze (Morris et al., 1990), as are lesions to subiculum (M orris et al., 1990), entorhinal cortex ( $N$ agahara et al., 1995; Schenk and M orris, 1985), postsubiculum (Taube et al., 1992), and fornix (Eichenbaum et al., 1990; Sutherland and Rodriguez, 1990; Packard and M CGaugh, 1992).

It is also possible that the hippocampus is necessary for declarative memory and the location of the animal is only one aspect of that more extensive system. Supporting this hypothesis are data showing that the firing rates of hippocampal pyramidal cells ("place" cells) are correlated with information other than location of the animal: speed, direction, turning angle ( $\mathrm{M} \mathrm{CN}$ aughton et al., 1983a; M arkus et al., 1994; W iener et al., 1989), texture underfoot (Young et al., 1994), odor (Eichenbaum et al., 1987), task (M arkus et al., 1995), and stage of task (Eichenbaum et al., 1987; $\mathrm{H}$ ampson et al., 1993; O tto and Eichenbaum, 1992). But the extensiveness of these correlations has not been tested. Recently, Skaggs et al. (1993) proposed a measure of the information communicated about location by a spike of a place cell. It is straightforward to extend this measure to non-location cues (Skaggs et al., 1993). O ne way to test the hypothesis that location is only one aspect of a more extensive memory system is to show that this other information is as well represented as location in the place cell firing rate.

Even if the locale navigation system is a subset of the declarative memory functions subserved by thehippocampus, by understanding the role the hippocampus plays in navigation, we can gain insight into its declarative memory functions. In this paper, we have proposed the concept of reference frames as a means of understanding place cell correlations with non-spatial factors such as environment, task, and stage of task. We have also suggested means by which the head direction system can interact with the place code. A place cell tuned to location, heading, reference frame, task, and stage of task would carry all the information necessary to encode an episode. Reference frames may be a way of unifying the navigation and episodic memory theories of hippocampal function.

\section{Acknowledgments}

We thank Jeffrey Taube and Pat Sharp for their critical readings of an earlier draft of this paper, Tad Blair, Kati G othard, M ichael $\mathrm{H}$ asselmo, and Bruce $\mathrm{MCN}$ aughton for helpful discussions, and two anonymous reviewers for their insightful comments.

$D$ avid Redish was partially supported by the $N$ eural Processes in Cognition Graduate Training Program (N SF grant BIR9014347) and by a National Science Foundation graduate fellowship. 


\section{REFERENCES}

Abraham L, Potegal M, M iller S (1983) Evidence for caudate nucleus involvement in an egocentric spatial task: Return from passive transport. Physiol Psychol 11(1):11-17.

Aggleton JP (1993) The contribution of the amygdala to normal and abnormal emotional states. Trends N eurosci 1(8):328-333.

Alyan SH , Jander R (1994) Short-range homing in the house mouse M us musculus: Stages in the learning of directions. Anim Behav 48(2):285298.

Amaral DG (1993) Emerging principles of intrinsic hippocampal organization. Curr O pin N eurobiol 3:225-229.

Anderson JA, H inton GE (1981) M odels of information processing in the brain. In: Parallel models of associative memory, (H inton GE, Anderson JA, eds), pp 9-48. Hillsdale, N J : Lawrence Erlbaum.

Annett LE, M cG regor A, RobbinsT W (1989) The effects of ibotenic acid lesions of the nucleus accumbens on spatial learning and extinction in the rat. Behav Brain Res 31(3):231-242.

Austin KB, W hite LH, Shapiro M L (1993) Short- and long-term effects of experience on hippocampal place fields. Soc Neurosci Abstr 19:797.

Barnes CA, M CN aughton BL, M izumori SJY, Leonard BW, Lin LH (1990) Comparison of spatial and temporal characteristics of neuronal activity in sequential stages of hippocampal processing. In: Understanding the brain through the hippocampus: The hippocampal region as a model for studying brain structure and function (Storm-M athisen J, Zimmer J, 0 ttersen O P, eds), vol 83 of Progressin brain research, pp 287-300. N ew York: Elsevier.

Bentivoglio M, Kultas-Ilinsky K, Illinsky I (1993) Limbic thalamus: Structure, intrinsic organisation, and connections. In: N eurobiology of cingulate cortex and limbic thalamus: A comprehensive handbook, (Vogt BA, Gabriel M , eds), pp 71-122. Boston: Birkhauser.

Beritashvili IS (1965) N eural mechanisms of higher vertebrate behavior. Boston: Little, Brown.

Blair HT, Sharp PE (1995a) Anticipatory head direction signals in anterior thalamus: Evidence for a thalamocortical circuit that integrates angular head motion to compute head direction. J Neurosci 15(9):6260-6270.

Blair HT, Sharp PE (1995b) Visual and vestibular influences on head-direction cells in the anterior thalamus of the rat. M anuscript.

Bostock E, M uller RU, KubieJL (1991) Experience-dependent modifications of hippocampal place cell firing. H ippocampus 1(2):193-206.

Brown M A, Sharp PE (1995) Simulation of spatial learning in the M orris water maze by a neural network model of the hippocampal formation and nucleus accumbens. H ippocampus 5(3):171-188.

Buhot M -C, N aili S (1995) Changes in exploratory activity following stimulation of hippocampal 5-H T $1 \mathrm{~A}$ and $5-\mathrm{HT} 1 \mathrm{~B}$ receptors in the rat. H ippocampus 5(3):198-208.

Buzsaki G (1989) Two-stage model of memory trace formation: A rolefor "noisy" brain states. N euroscience 31(3):551-570.

Carr $H$ (1917) Maze studies with the white rat. J Anim Behav 7:259-306.

Carr H, Watson JB (1908) O rientation in the white rat. J Comp N eurol Psychol 18:27-44.

Chen LL (1991) Head-directional information processing in the rat posterior cortical areas. PhD thesis, University of Colorado.

Chen LL, Lin LH, Barnes CA, M CN aughton BL (1994a) H ead-direction cells in the rat posterior cortex: II. Contributions of visual and ideothetic information to the directional firing. Exp Brain Res 101:24-34.

Chen LL, Lin LH, Green EJ, Barnes CA, M CN aughton BL (1994b) Head-direction cells in the rat posterior cortex: I. Anatomical distribution and behavioral modulation. Exp Brain Res 101:8-23.

Cheng K (1986) A purely geometric module in the rat's spatial representation. Cognition 23:149-178.
Cohen N J, Eichenbaum H (1993) M emory, amnesia, and the hippocampal system. Cambridge, M A: M IT Press.

Cooper JR, Bloom FE, Roth RH (1986) The biochemical basis of neuropharmacology, 5th ed. N ew York: O xford U niversity Press.

Crino PB, M orrison JH , H of PR (1993) M onoaminergic innervation of cingulate cortex. In: N eurobiology of cingulate cortex and limbic thalamus: A comprehensive handbook, (Vogt BA, G abriel M , eds), pp 285-310. Boston: Birkhauser.

Davis M, Rainnie D, Cassell M (1994) Neurotransmission in the rat amygdala related to fear and anxiety. Trends N eurosci 17(5):208-214.

Domesick VB (1981) Further observations on the anatomy of nucleus accumbens and caudatoputamen in the rat: Similarities and contrasts. In: The neurobiology of the nucleus accumbens (Chronister RB, de France JF, eds). Brunswick, $\mathrm{M}$ e: $\mathrm{H}$ aer Institute for Electrophysiological Research.

Eichenbaum H, Kuperstein M, Fagan A, N agodeJ (1987) Cue-sampling and goal-approach correlates of hippocampal unit activity in rats performing an odor-discrimination task. J N eurosci 7(3):716-732.

Eichenbaum H, O tto T, Cohen NJ (1992) The hippocampus- what does it do? Behav N eural Biol 57:2-36.

Eichenbaum H , Stewart C, M orris RG M (1990) H ippocampal representation in place learning. J N eurosci 10(11):3531-3542.

Etienne AS (1987) The control of short-distance homing in the golden hamster. In: Cognitive processes and spatial orientation in animals and man (Ellen P, Thinus-Blanc C, eds), pp 233-251, Boston: $M$ artinus $N$ ijhoff.

Etienne AS (1992) N avigation of a small mammal by dead reckoning and local cues. Curr D irections Psychol Sci 1(2):48-52.

Finch D M (1993) H ippocampal, subiculuar, and entorhinal afferents and synaptic integration in rodent cingulate cortex. In: N eurobiology of cingulate cortex and limbic thalamus: A comprehensive handbook (Vogt BA, Gabriel M, eds), pp 224-248. Boston: Birkhauser.

Fox SE, Ranck JB Jr (1981) Electrophysiological characteristics of hippocampal complex-spike cells and theta cells. Exp Brain Res 41:399-410.

Gallistel CR (1990) The O rganization of learning. Cambridge, M A: M IT Press.

Georgopoulos AP, Caminiti R, Kalaska JF, M assey JT (1983) Spatial coding of movement: A hypothesis concerning the coding of movement direction by motor cortical populations. Exp Brain Res Supplement (7):327-336.

Gluck MA, M yers CE (1993) H ippocampal mediation of stimulus representation: A computational theory. H ippocampus 3(4):491516.

Golob EJ, Taube JS (1994) Head direction cells recorded from the postsubiculum in animals with lesions of the lateral dorsal thalamic nucleus. Soc N eurosci Abstr 20(1):805.

Goodridge JP, Taube JS (1994) The effect of lesions of the postsubiculum on head direction cell firing in the anterior thalamic nuclei. Soc N eurosci Abstr 20(1):805.

Goodridge JP, Taube JS (1995) Preferential use of the landmark navigational system by head direction cells in rats. Behav N eurosci 109(1):49-61.

Gothard KM, Skaggs WE, Moore KM, MCNaughton BL (1994) Behavioral correlates of hippocampal CA1 cells in a landmark navigation task. Soc N eurosci Abstr 20:1207.

Gothard KM , Skaggs WE, M cN aughton BL (1995) Interactions between multiple spatial reference frames in the rat hippocampus. Soc N eurosci Abstr 21:941.

Gothard KM , Skaggs W E, M oore KM , M cN aughton BL (1996) Binding of hippocampal cal neural activity to multiple reference frames in a landmark-based navigation task. J N eurosci 16(2):823-835.

Gray JA (1982) The neuropsychology of anxiety: An enquiry into the functions of the septo-hippocampal system. New York: Oxford University Press.

Grossberg S (1976) Adaptive pattern classification and universal recod- 
ing: I. Parallel development and coding of neural feature detectors. Biol Cybernet 23:121-134.

H ampson RE, H eyser CJ, D eadwyler SA (1993) H ippocampal cell firing correlates of delayed-match-to-sample performance in the rat. Behav Neurosci 107(5):715-739.

$\mathrm{H}$ asselmo M E (1993) Acetylcholine and learning in a cortical associative memory. N eural Comput 5:32-44.

$\mathrm{H}$ asselmo M E (1995) N euromodulation and cortical function: M odeling the physiological basis of behavior. Behav Brain Res 67(1):1-27.

$\mathrm{H}$ asselmo M E, Bower JM (1993) Acetylcholine and memory. Trends Neurosci 16(6):218-222.

$\mathrm{H}$ asselmo ME, Schnell E (1994) Laminar selectivity of the cholinergic suppression of synaptic transmission in rat hippocampal region CA1: Computational modeling and brain slice physiology. J Neurosci 14(6):3898-3914.

Hill AJ (1978) First occurrence of hippocampal spatial firing in a new environment. Exp N eurol 62:282-297.

I saacson RL (1974) The limbic system. N ew York: Plenum.

Jaffard R, Beracochea D, Cho Y (1991) The hippocampal-mamillary system: Anterogradeand retrograde amnesia. H ippocampus 1(3):275278.

Jones D L, M ogenson GJ (1980) N ucleus accumbens to globus pallidus GABA projection subserving ambulatory activity. Am J Physiol 238:R65-R69.

Jones RSG (1993) Entorhinal-hippocampal connections: a speculative view of their function. Trends N eurosci 16(2):58-64.

Jung M W, M CN aughton BL (1993) Spatial selectivity of unit activity in the hippocampal granular layer. H ippocampus 3:165-182.

Kiyatkin EA, G ratton A (1994) Electrochemical monitoring of extracellular dopamine in nucleus accumbens of rats lever-pressing for food. Brain Res 652:225-234.

Knierim JJ, Kudrimoti HS, M CNaughton BL (1995) Place cells, head direction cells, and the learning of landmark stability. J Neurosci 15:1648-1659.

Kohler C (1986) Intrinsic connections of the retrohippocampal region in the rat brain. II. The medial entorhinal area. J Comp Neurol 246:149-169.

Kohler C (1988) Intrinsic connections of the retrohippocampal region in the rat brain. III. The lateral entorhinal area. J Comp Neurol 271:208-228.

Kohonen T (1977) Associative memory: A system-theoretical approach. N ew York: Springer-Verlag.

Kohonen T (1980) C ontent-addressable memories. N ew York: SpringerVerlag.

Kohonen T (1984) Self-organization and associative memory. N ew York: Springer-Verlag.

Krieg W JS (1946) Connections of the cerebral cortex. I. The albino rat: A. Topography of the cortical areas. J Comp Neurol 84:221-275. Cited in Chen et al., 1994b.

Kubie JL, Ranck JB Jr (1983) Sensory-behavioral correlates in individual hippocampus neurons in three situations: Space and context. In: N eurobiology of the hippocampus (Seifert W, ed), pp 433-447. N ew York: Academic.

Kubie JL, Muller RU, Bostock E (1990) Spatial firing properties of hippocampal theta cells. J N eurosci 10(4):1110-1123.

Lacaille J-C, Kunkey DD , Schwartzkroin PA (1989) Electrophysiological and morphological characterization of hippocampal interneurons. In: The hippocampus- new vistas (Chan-Palay V, Kohler C, eds), pp 287-306. N ew York: Alan R. Liss.

Landfield PW, Deadwyler SA (eds) (1988) Long-term pontentiation: From biophysics to behavior, vol. 35 of N eurology and neurobiology. New York: Alan R. Liss.

Lavoie AM, M izumori SJY (1994) Spatial, movement- and rewardsensitive discharge by medial ventral striatum neurons in rats. Brain Res 638:157-168.

Leonard B, M CN aughton BL (1990) Spatial representation in the rat: Conceptual, behavioral, and neurophysiological perspectives. In:
N eurobiology of comparative cognition (Kesner RP, OIton DS, eds), pp 363-422. H illsdale, N J: Lawrence Earlbaum.

M arkus EJ, Barnes CA, M cNaughton BL, Gladden VL, Skaggs WE (1994) Spatial information content and reliability of hippocampal CA1 neurons: Effects of visual input. $\mathrm{H}$ ippocampus 4:410-421.

$M$ arkus EJ, Q in Y, Leonard B, Skaggs W E, M cN aughton BL, Barnes CA (1995) Interactions between location and task affect the spatial and directional firing of hippocampal neurons. J N euroscience, in press.

M arr D (1969) Simple memory: A theory for archicortex. PhilosTrans R Soc Lond [B] 262:23-81.

M aurer R, Seguinot V (1995) What is modelling for? A critical review of the models of path integration. J Theor Biol 175:457-475.

McClelland JL, M cN aughton BL, O'Reilly RC (1995) W hy there are complementary learning systems in the hippocampus and neocortex: Insights from the successes and failures of connectionist models of learning and memory. Psychol Rev 102(3):419-457.

M cD onald RJ, W hite N M (1994) Parallel information processing in the water maze: Evidence for independent memory systems involving dorsal striatum and hippocampus. Behav N eural Biol 61:260-270.

M cN aughton BL (1989) N euronal mechanisms for spatial computation and information storage. In: N eural connections. M ental computation (Nadel L, Cooper L, Culicover P, Harnish RM, eds), pp 285-350. Cambridge, M A: M IT Press.

M cN aughton BL, M orris RGM (1987) H ippocampal synaptic enhancement and information storage within a distributed memory system. Trends N eurosci 10(10):408-415.

McNaughton BL, Nadel L (1990) Hebb-M arr networks and the neurobiological representation of action in space. In: Neuroscience and connectionist theory (Gluck M A, Rumelhart DE, eds), pp 1-63. $\mathrm{H}$ illsdale, $\mathrm{N}$ J: Lawrence Erlbaum.

M cN aughton BL, Barnes CA, O 'Keefe J (1983a) The contributions of position, direction, and velocity to single unit activity in the hippocampus of freely-moving rats. Exp Brain Res 52:41-49.

M cN aughton BL, 0 'Keefe J, Barnes CA (1983b) The stereotrode: A new technique for simultaneous isolation of several single units in the central nervous system from multiple unit records. J Neurosci M ethods 8:391-397.

McN aughton BL, Leonard B, Chen L (1989) Cortical-hippocampal interactions and cognitive mapping: $A$ hypothesis based on reintegration of the parietal and inferotemporal pathways for visual processing. Psychobiology 17(3):230-235.

MCNaughton BL, Chen LL, M arkus EJ (1991) "D ead reckoning," landmark learning, and the sense of direction: A neurophysiological and computational hypothesis. J Cogn N eurosci 3(2):190-202.

M cN aughton BL, Knierim JJ, W ilson M A (1994a) Vector encoding and the vestibular foundations of spatial cognition: Neurophysiological and computational mechanisms. In: The cognitive neurosciences (Gazzaniga M , ed), pp 585-595. Boston: M IT Press.

M cN aughton BL, M izumori SJY, Barnes CA, Leonard BJ, M arquis M, Green EJ (1994b) Cortical representation of motion during unrestrained spatial navigation in the rat. Cerebral Cortex 4(1):27-39.

McNaughton BL, Barnes CA, Gerrard JL, Gothard K, Jung MW, Knierim JJ, Kudrimoti $H$, Q in $Y$, Skaggs WE, Suster $M$, Weaver $K L$ (1996) D eciphering the hippocampal polyglot: The hippocampus as a path integration system. J Exp Biol 199(1):173-186.

$M$ ' $H$ arzi $M$, Palacios $A$, M onmaur $P$, W illig F, H oucine $O$, D elacour J (1987) Effects of selective lesions of fimbria-fornix on learning set in the rat. Physiol Behav 40:181-188.

M iller V M , Best PJ (1980) Spatial correlates of hippocampal unit activity are altered by lesions of the fornix and entorhinal cortex. Brain Res 194:311-323.

M ittelstaedt $H$ (1983) T he role of multimodal convergence in homing by path integration. In: Multimodal convergences in sensory systems (H orn E, ed), vol. 28 of Fortschritte der Zoologie, pp 197-212. N ew York: Gustav Fischer Verlag.

M ittelstaedt M L, M ittelstaedt H (1980) H oming by path integration in a mammal. N aturwissenschaften 67:566-567. 
Mizumori SJY, Cooper BG (1995) Spatial representations of dorsal caudate neurons of freely-behaving rats. Soc N eurosci Abstr 21:1929.

M izumori SJY, Williams JD (1993) D irectionally selective mnemonic properties of neurons in the lateral dorsal nucleus of the thalamus of rats. J N eurosci 13(9):4015-4028.

M izumori SJY, Barnes CA, M cN aughton BL (1990) Behavioral correlates of theta-on and theta-off cells recorded from hippocampal formation of mature young and aged rats. Exp Brain Res 80:365-373.

M izumori SJY, Ward KE, Lavoie AM (1992) M edial septal modulation of entorhinal single unit activity in anesthetized and freely moving rats. Brain Res 570:188-197.

Mogenson GJ (1984) Limbic-motor integration- with emphasis on initiation of exploratory and goal-directed locamotion. In: M odulation of sensorimotor activity during alterations in behavioral states (Bandler R, ed), pp 121-138. N ew York: Alan R. Liss.

Mogenson GJ, Nielsen M (1984) Neuropharmacological evidence to suggest that the nucleus accumbens and subpallidal region contribute to exploratory locomotion. Behav N eural Biol 42:52-60.

M orris RGM (1981) Spatial localization does not require the presence of local cues. Learning M otivation, 12:239-260.

M orrisRG M , Schenk F, Tweedie F, Jarrard LE (1990) Ibotenate lesions of hippocampus and/or subiculum: $D$ issociating components of allocentric spatial learning. Eur J N eurosci 2:1016-1028.

Muller RU, Kubie JL (1987) The effects of changes in the environment on the spatial firing of hippocampal complex-spike cells. J N eurosci 7:1951-1968.

Muller RU, Kubie JL, Ranck JB Jr (1987) Spatial firing patterns of hippocampal complex-spike cells in a fixed environment. J N eurosci 7:1935-1950.

Muller RU, Kubie JL, Bostock EM , Taube JS, Q uirk GJ (1991a) Spatial firing correlates of neurons in the hippocampal formation of freely moving rats. In: Brain and space (Paillard J, ed), pp 296-333. N ew York: O xford University Press.

M uller RU , Kubie JL, Saypoff R (1991b) The hippocampus as a cognitive graph. H ippocampus 1(3):243-246.

Muller RU, Bostock E, Taube JS, Kubie JL (1994) On the directional firing properties of hippocampal place cells. J N eurosci 14(12):72357251.

Muller RU, Stead M, Pach J (1995) The hippocampus as a cognitive graph. M anuscript.

N agahara AH , O tto T, G allagher M (1995) Entorhinal-perirhinal lesions impair performance of rats on two versions of place learning in the morris water maze. Behav N eurosci 109(1):3-9.

N eave N, Lloyd S, Sahgal A, Aggleton JP (1994) Lack of effect of lesions in the anterior cingulate cortex and retrosplenial cortex on certain tests of spatial memory in the rat. Behav Brain Res 65:89-101.

Nilsson OG, Shapiro ML, Gage FH, OIton DS, Bjorklund A (1987) Spatial learning and memory following fimbria-fornix transection and grafting of fetal septal neurons to the hippocampus. Exp Brain Res 67:195-215.

0 'K eefe (1976) Place units in the hippocampus of the freely moving rat. Exp N eurol 51:78-109.

0 'Keefe J, Conway DH (1978) H ippocampal place units in the freely moving rat: W hy they fire where they fire. Exp Brain Res 31:573-590.

0 'Keefe J, Dostrovsky J (1971) The hippocampus as a spatial map. Preliminary evidence from unit activity in the freely moving rat. Exp Brain Res 34:171-175.

0 'K eefe J, N adel L (1978) The hippocampus as a cognitive map. O xford: Clarendon.

0 'Keefe J, Speakman A (1987) Single unit activity in the rat hippocampus during a spatial memory task. Exp Brain Res 68:1-27.

0 'Reilly RC, M cClelland JL (1994) H ippocampal conjunctive encoding, storage, and recall: avoiding a trade-off. H ippocampus 4(6):661-682.

$\mathrm{O}$ tto T, Eichenbaum $\mathrm{H}$ (1992) Neuronal activity in the hippocampus during delayed non-match to sample performance in rats: Evidence for hippocampal processing in recognition memory. Hippocampus 2(3):323-334.
Packard M G, M cGaugh JL (1992) Double dissociation of fornix and caudate nucleus lesions on acquisition of two water maze tasks: Further evidence for multiple memory systems. Behav Neurosci 106(3):439-446.

Packard M G, Cahill L, M cGaugh JL (1991) Amygdala modulation of hippocampal-dependent memory processes. Proc N atl Acad Sci USA 91:8477-8481.

Papez JW (1937) A proposed mechanism of emotion. Arch N eurol Psychiatry 38:728-744.

Pico RM , G erbrandt LK, Pondel M , Ivy G (1985) During stepwise cue deletion, rat place behaviors correlate with place unit responses. Brain Res 330:369-372.

Potegal M (1982) Vestibular and neostriatal contributions to spatial orientation. In: Spatial abilities: Development and physiological foundations (Potegal M , ed), pp 361-387, N ew York: Academic.

Poucet B, Chapuis N, Durup M, Thinus-Blanc C (1986) A study of exploratory behavior as an index of spatial knowledge in hamsters. Anim Learning Behav 14(1):93-100.

Pouget A, Sejnowski TJ (1995) Spatial representations in parietal cortex may use basis functions. In: Advances in neural information processing systems 7. (Tesauro G, Touretzky D, Leen T, eds), Cambridge, $M$ A: M IT Press.

Q uirk GJ, M uller RU, Kubie JL (1990) The firing of hippocampal place cells in the dark depends on the rat's recent experience. J N eurosci 10(6):2008-2017.

Q uirk GJ, M uller RU , Kubie JL, Ranck JB Jr (1992) T hepositional firing properties of medial entorhinal neurons: $D$ escription and comparison with hippocampal place cells. J N eurosci 12(5):1945-1963.

Ranck JB Jr (1973) Studies on single neurons in dorsal hippocampus formation and septum in unrestrained rats. I. Behavioral correlates and firing repertoires. Exper $\mathrm{N}$ eurol 41:461-555.

Redish AD, Touretzky D S (1994) The reaching task: Evidence for vector arithmetic in the motor system? Biol Cybernet 71:307-317.

Redish AD, Touretzky DS (1996) N avigating with landmarks: Computing goal locations from place codes. In: Symbolic visual learning (I keuchi K, Veloso M, eds), New York: Oxford U niversity Press, in press.

Rolls ET (1989) The representation and storage of information in neuronal networks in the primate cerebral cortex and hippocampus. In: The computing neuron (D urbin R, M iall C, M itchison $G$, eds), pp 125-159. Reading, M A: Addison-Wesley.

Rumelhart DE, Zipser D (1986) Feature discovery by competitive learning. In: Parallel distributed processing: Explorations in the microstructure of cognition. Vol. 1: Foundations, pp 151-193. Cambridge, M A: M IT Press.

Samsonovich A, M cN aughton BL (1995) M illisecond temporal structure of memory representations and hippocampal-dependent cognitive mechanisms. Soc N eurosci Abstr 21:942.

Schenk F, M orris RGM (1985) Dissociation between components of spatial memory in rats after recovery from the effects of retrohippocampal lesions. Exp Brain Res 58:11-28.

Schwartzkroin PA, Scharfman HE, Sloviter RS (1990) Similarities in circuitry between Ammon's horn and dentate gyrus: Local interactions and parallel processing. In: U nderstanding the brain through the hippocampus: The hippocampal region as a model for studying brain structure and function (Storm-M athisen J, Zimmer J, O ttersen O P, eds), vol. 83 of Progress in brain research, pp 269-286. N ew York: Elsevier.

Scoville W B, M ilner B (1957) Loss of recent memory after bilateral hippocampal lesions. J N eurol N eurosurg Psychiatry 20:11-21.

Shapiro M L, Simon DK, O Iton DS, Gage FH III, N ilsson O, Bjorklund A (1989) Intrahippocampal grafts of fetal basal forebrain tissue alter place fields in the hippocampus of rats with fimbria-fornix lesions. N euroscience 32(1):1-18.

Sharp PE (1991) Computer simulation of hippocampal place cells. Psychobiology 19(2):103-115.

Sharp PE (1995) Subicular cells generate similar firing patterns in two 
geometrically and visually distinctive environments: Comparison with hippocampal place cells. M anuscript.

Sharp PE, Green C (1994) Spatial correlates of firing patterns of single cells in the subiculum of the freely moving rat. J N eurosci 14(4):23392356.

Sharp PE, Blair HT, Etkin D, Tzanetos DB (1995) Influences of vestibular and visual motion information on the spatial firing patterns of hippocampal place cells. J N eurosci 15(1):173-189.

Skaggs WE, M CN aughton BL, Gothard KM, M arkus EJ (1993) An information theoretic approach to deciphering the hippocampal code. In: Advances in neural information processing systems 5 (H anson $\mathrm{S}$, Cowan J, Giles L, eds), pp 1030-1037. San Mateo, CA: Morgan Kaufmann.

Squire LR, Zola-M organ S (1988) M emory: Brain systems and behavior. Trends N eurosci 11(4):170-175.

Stewart M , Fox SE (1990) D o septal neurons pace the hippocampal theta rhythm? Trends N eurosci 13(5):163-168.

Sutherland RJ , H oesing JM (1993) Posterior cingulate cortex and spatial memory: A microlimnology analysis. In: N eurobiology of cingulate cortex and limbic thalamus: A comprehensive handbook (Vogt BA, Gabriel M , eds), pp 461-477. Boston: Birkhauser.

Sutherland RJ, Rodriguez AJ (1990) The role of the fornix/fimbria and some related subcortical structures in place learning and memory. Behav Brain Res 32:265-277.

Sutherland RJ, Rudy JW (1989) Configural association theory: The role of the hippocampal formation in learning, memory, and amnesia. Psychobiology 17(2):129-144.

Sutherland RJ, W hishaw IQ , and Regehr JC (1982) Cholinergic receptor blockade impairs spatial localization by use of distal cues in the rat. J Comp Physiol Psychol 96(4):563-573.

Sutherland RJ, W hishaw IQ, Kolb B (1988) Contributions of cingulate cortex to two forms of spatial learning and memory. J Neurosci 8(6):1863-1872.

Suzuki S, Augerinos G, Black AH (1980) Stimulus control of spatial behavior on the eight-arm maze in rats. Learning $M$ otivation 11:1-18.

Sziklas V, Petrides M (1993) M emory impairments following lesions to the mammillary region of the rat. Eur J N eurosci 5:525-540.

Taube JS (1995) H ead direction cells recorded in the anterior thalamic nuclei of freely moving rats. J N eurosci 15(1):1953-1971.

Taube JS (1996) Place cells recorded in the parasubiculum of freely moving rats. H ippocampus 5(6).

Taube JS, Burton HL (1995) H ead direction cell activity monitored in a novel environment and during a cue conflict situation. J N europhysiol 74(5):1953-1971.

Taube JS, Muller RU (1995) H ead direction cell activity in the anterior thalamic nuclei, but not the postsubiculum, predicts the animal's future directional heading. Soc N eurosci Abtr 21:946.

Taube JS, M uller RI, Ranck JB Jr (1990a) H ead direction cells recorded from the postsubiculum in freely moving rats. I. Description and quantitative analysis. J N eurosci 10:420-435.

Taube JS, M uller RI, Ranck JB Jr (1990b) H ead direction cells recorded from the postsubiculum in freely moving rats. II. Effects of environmental manipulations. J N eurosci 10:436-447.

Taube JS, K lesslak JP, C otman CW (1992) Lesions of the rat postsubiculum impair performance on spatial tasks. Behav Neural Biol 5:131143.

Thinus-Blanc $C$, Bouzouba $L, C$ haix $K, C$ hapuis N , D urup $M$, Poucet $B$ (1987) A study of spatial parameters encoded during exploration in hamsters. J Exp Psychol 13(4):418-427.

Thinus-Blanc C, Save E, Buhot M C, Poucet B (1991) The hippocampus, exploratory activity, and spatial memory. In Brain and space (Paillard J, ed), pp 334- 352. N ew York: Oxford University Press.

Thinus-Blanc C, Durup M, Poucet B (1992) The spatial parameters encoded by hamsters during exploration: $A$ further study. Behav Proc 26:43-57.
Thompson LT, Best PJ (1989) Place cells and silent cells in the hippocampus of freely-behaving rats. J N eurosci 9(7):2382-2390.

Tolman EC (1948) Cognitive maps in rats and men. Psychol Rev 55:189-208.

Touretzky DS, Redish AD (1996) A theory of rodent navigation based on interacting representations of space. $\mathrm{H}$ ippocampus 6:247-270.

Touretzky DS, Redish AD, Wan HS (1993) Neural representation of space using sinusoidal arrays. N eural Comput 5(6):869-884.

van Groen T, Wyss JM (1990) The postsubicular cortex in the rat: Characterization of the fourth region of the subicular cortex and its connections. Brain Res 529:165-177.

Vogt BA (1985) Cingulate cortex. In: Association and auditory cortices (Peters A, Jones E, eds), vol. 4 of Cerebral cortex, pp 89-150. N ew York: Plenum.

Wan HS, Touretzky D S, Redish AD (1994a) A rodent navigation model that combines place code, head direction, and path integration information. Soc N eurosci Abstr 20:1205.

Wan HS, Touretzky DS, Redish AD (1994b) Towards a computational theory of rat navigation. In: Proceedings of the 1993 Connectionist M odels Summer School (M ozer M, Smolensky P, Touretzky D, Elman J, Weigend A, eds), pp 11-19, H illsdale, N J: LawrenceEarlbaum.

Watson JB (1907) K inaesthetic and organic sensations: Their role in the reactions of the white rat to the maze. Psychol Rev 8(2):43-100.

Wehner R, Srinivasan MV (1981) Searching behavior of desert ants, genus Cataglyphis (Formicidae, Hymenera). J Comp Physiol A 142:315-338.

Whishaw IQ (1985) Cholinergic receptor blockade in the rat impairs locale but not taxon strategies for place navigation in a swimming pool. Behav Neurosci 99(5):979-1005.

W hishaw IQ , M ittleman G (1991) H ippocampal modulation of nucleus accumbens: Behavioral evidence from amphetamine-induced activity profiles. Behav N eural Biol 55:289-306.

Whishaw IQ, Cassel J-C, Jarrard LE (1995) Rats with fimbria-fornix lesions display a place response in a swimming pool: A dissociation between getting there and knowing where. J Neurosci 15(8):57795788.

Wickens], Kotter R (1995) Cellular models of reinforcement. In: M odels of information processing in the basal ganglia (Houk JC, D avis J L, Besier D G, eds), pp 187-214, C ambridge, M A: M IT Press.

W iener SI (1993) Spatial and behavioral correlates of striatal neurons in rats performing a self-initiated navigation task. J N eurosci 13(9):38023817.

Wiener SI, Paul CA, Eichenbaum H (1989) Spatial and behavioral correlates of hippocampal neuronal activity. J Neurosci 9(8):27372783.

Wilson M A, M cNaughton BL (1993) Dynamics of the hippocampal ensemble code for space. Science 261:1055-1058.

Wilson MA, M cN aughton BL (1994) Reactivation of hippocampal ensemble memories during sleep. Science 265:676-679.

Witter M P (1993) O rganization of the entorhinal-hippocampal system: A review of current anatomical data. H ippocampus 3:33- 44.

W itter M P, O stendorf RH , G roenwegen HJ (1990) H eterogeneity in the dorsal subiculum of the rat: Distinct neuronal zones project to different cortical and subcortical targets. Eur J N eurosci 2:718-725.

Wolske M , Rompre PP, W ise RA, West M O (1993) Activation of single neurons in the rat nucleus accumbens during self-stimulation of the ventral tegmental area. J N eurosci 13(1):1-12.

Wyss JM, van Groen T (1992) Connections between the retrosplenial cortex and the hippocampal formation in the rat: A review. H ippocampus 2(1):1-12.

Young BJ, Fox GD, Eichenbaum H (1994) Correlates of hippocampal complex-spike cell activity in rats performing a nonspatial radial maze task. J N eurosci 14(11):6553-6563.

Zilles KJ (1985) The cortex of the rat: A stereotaxis atlas. N ew York: Springer-Verlag. Cited in Chen et al., 1994b.

Zola-M organ S, Squire LR (1993) N euroanatomy of memory. Ann Rev N eurosci 16:547-563. 